\title{
MODELING THE EFFECT OF PERCEIVED EASE OF USE ON VIRTUAL TEAM PERFORMANCE
}

\author{
By \\ Nuket Savaskan Nowlan, B.Sc. \\ A thesis submitted to the Faculty of Graduate and Postdoctoral Affairs \\ in partial fulfillment of the requirements for the degree of \\ Master of Applied Science in Technology Innovation Management \\ Department of Systems and Computer Engineering \\ Carleton University \\ Ottawa, Canada, K1S 5B6
}

August 2011

(C) Copyright 2011, Nuket Savaskan Nowlan 
Library and Archives

Canada

Published Heritage

Branch

395 Wellington Street

Ottawa ON K1A 0N4

Canada
Bibliothèque et

Archives Canada

Direction du

Patrimoine de l'édition

395 , rue Wellington

Ottawa ON K1A ON4

Canada
Your file Votre référence

ISBN: 978-0-494-83045-1

Our file Notre référence

ISBN: 978-0-494-83045-1
NOTICE:

The author has granted a nonexclusive license allowing Library and Archives Canada to reproduce, publish, archive, preserve, conserve, communicate to the public by telecommunication or on the Internet, loan, distribute and sell theses worldwide, for commercial or noncommercial purposes, in microform, paper, electronic and/or any other formats.

The author retains copyright ownership and moral rights in this thesis. Neither the thesis nor substantial extracts from it may be printed or otherwise reproduced without the author's permission.
AVIS:

L'auteur a accordé une licence non exclusive permettant à la Bibliothèque et Archives Canada de reproduire, publier, archiver, sauvegarder, conserver, transmettre au public par télécommunication ou par l'Internet, prêter, distribuer et vendre des thèses partout dans le monde, à des fins commerciales ou autres, sur support microforme, papier, électronique et/ou autres formats.

L'auteur conserve la propriété du droit d'auteur et des droits moraux qui protège cette thèse. $\mathrm{Ni}$ la thèse ni des extraits substantiels de celle-ci ne doivent être imprimés ou autrement reproduits sans son autorisation.
In compliance with the Canadian Privacy Act some supporting forms may have been removed from this thesis.

While these forms may be included in the document page count, their removal does not represent any loss of content from the thesis.
Conformément à la loi canadienne sur la protection de la vie privée, quelques formulaires secondaires ont été enlevés de cette thèse.

Bien que ces formulaires aient inclus dans la pagination, il n'y aura aucun contenu manquant.

\section{Canadä}


The undersigned recommend to the Faculty of Graduate and Postdoctoral Affairs acceptance of the thesis

\section{MODELING THE EFFECT OF PERCEIVED EASE OF USE ON VIRTUAL TEAM PERFORMANCE}

submitted by

Nuket Savaskan Nowlan, B.Sc.

in partial fulfillment of the requirements for

the degree of Master of Applied Science in Technology Innovation Management

Chair, Howard Schwartz, Department of Systems and Computer Engineering

Thesis Supervisor, Ali Arya

Carleton University

August 2011 


\section{Abstract}

We have entered a new century in which communication and collaboration are almost impossible without using digital technology. In some cases digital technology is used to complement the physical collaboration media. In most cases, it is rapidly replacing it. Virtual teams are becoming a preferable organizational structure for companies to attract talent while avoiding relocation and overhead costs. Virtual team members rely on underlying digital media for their interaction; therefore, members need to perform their work interactions through the technology in use. There exists a wealth of research in the literature supporting a positive relationship between perceived ease of use of a technology and behavioural intention of use (BIU) of the same technology. It is always assumed that BIU also has a positive relationship with individual performance. However, not much research, that we have found, exists providing data supporting that theory.

In this study, an immersive virtual environment was designed for students from different disciplines to practice their team work skills. In the case of a domestic violence 911 call, an emergency team is formed with police officers, nurses, child care workers and paramedics. The newly formed team needs to collaborate and communicate effectively to handle the situation. An avatar-based virtual environment was designed to provide a simulation opportunity to team members. Visually, the virtual environment appears to the user as a campus with a series of buildings that avatars can enter and perform related simulations. A police station, fire hall, five houses and two government building created for that purpose as well as collaboration spaces and lecture hall. An 
auditorium is designed as well for group briefing and lecturing.

Sixty recent participants simulated their team work at both in person and in an immersive virtual environment, collectively, in real time. These simulations were recorded and evaluated by a group of experts. Participants' performance was evaluated both individually and as a team. The research team surveyed learners to understand perceived ease of use of the technology as well. Collected data was analyzed to identify relationships between perceived ease of use and individuals/team performance over team work skill dimensions such as; collaboration, communication, role and responsibilities, conflict management, and team functioning. We have identified a strong positive relationship between perceived ease of use and conflict management skill and overall performance. 


\section{Acknowledgement}

I would like to acknowledge and extend my heartfelt gratitude to the following persons who have made the completion of this thesis possible:

My supervisor, Dr. Ali Arya, for his tireless guidance and continuous support during my master study and my research. His encouragement, his support and his expertise in the area of my research interest made my study possible. I will always be thankful.

My professors have also enriched my education and research experiences at Carleton. I specifically would like to thank Professor Antonio Bailetti, Professor Michael Weiss, for their excellent comments and guidance they have provided during my study and my research.

My Algonquin research partners and friends, Dr. Eleanor Riesen and Michelle. Without their expertise and continues support this research cannot be completed.

My Carleton research partners Dr. Shawn Graham and Peggy Hartwick.

My husband John Nowlan for everything he has done to make my study possible.

My classmates and friends in the TIM program, for the endless hours we spent preparing assignments and presentations for our courses and which prepared me for the work of this thesis. They made the learning process much easier and enjoyable.

And above all, to my father Ismet Savaskan for the lifelong encouragement and love. 


\section{Table of Contents}

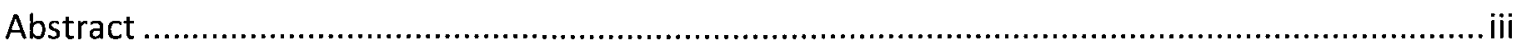

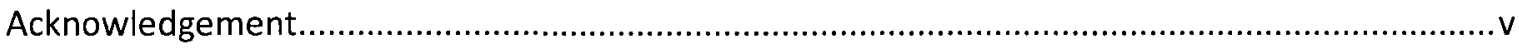

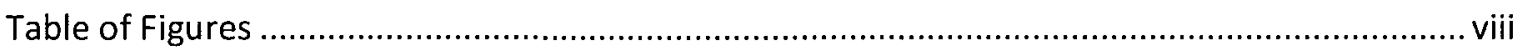

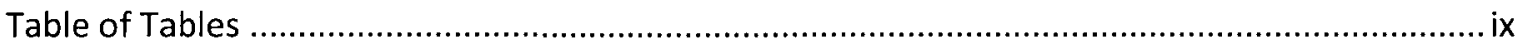

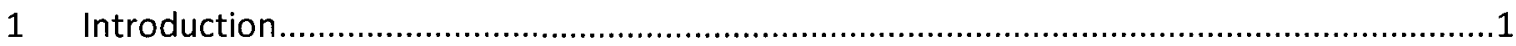

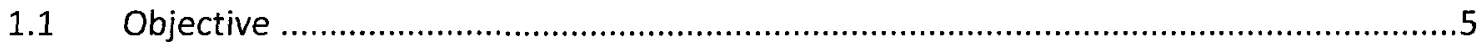

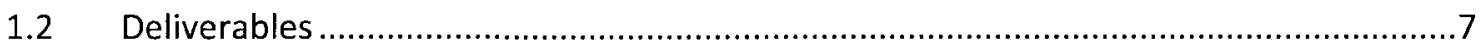

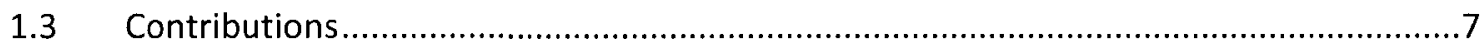

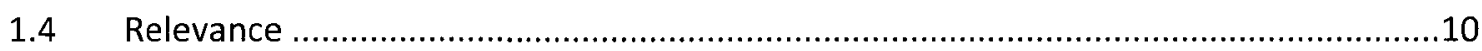

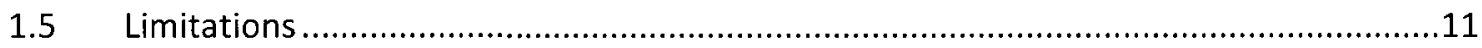

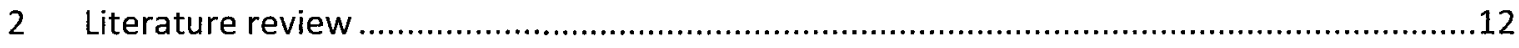

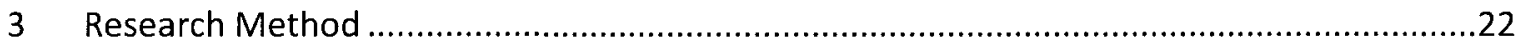

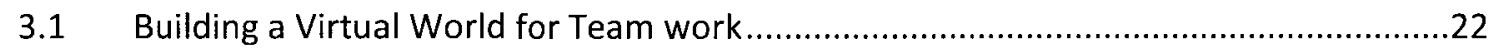

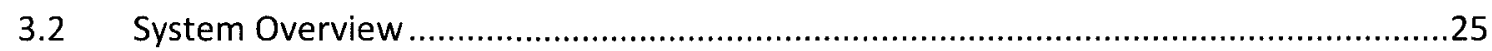

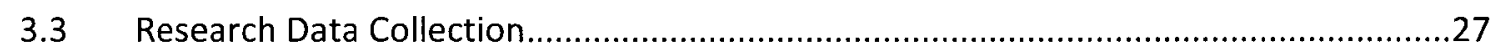

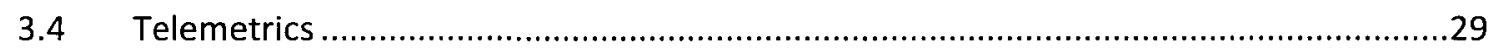

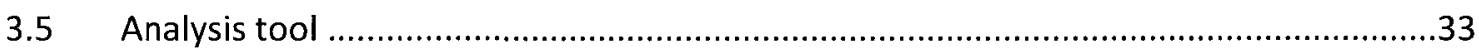

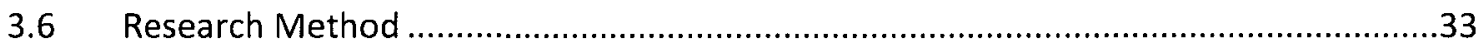

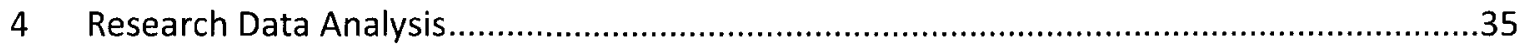

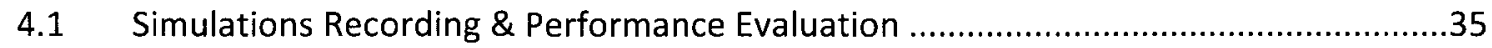

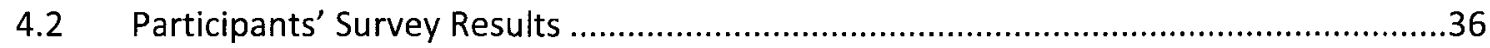

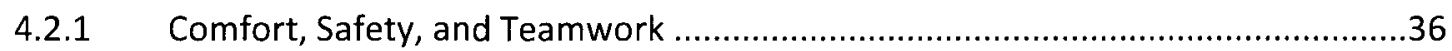

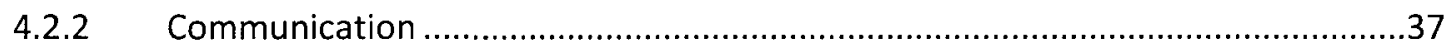

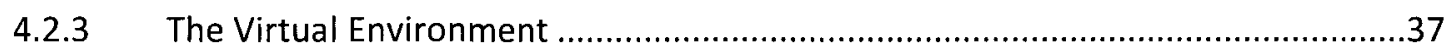




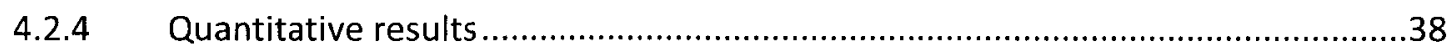

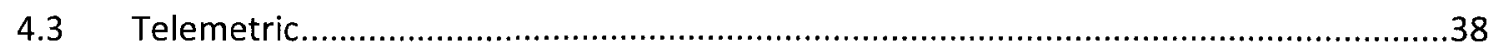

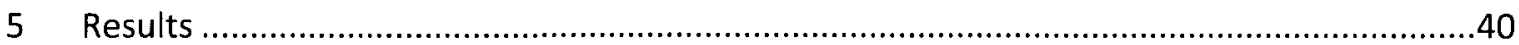

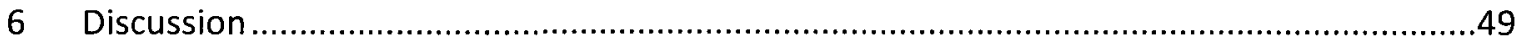

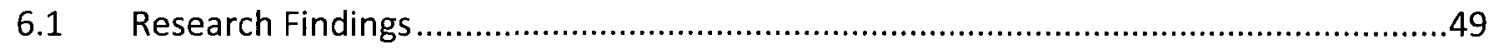

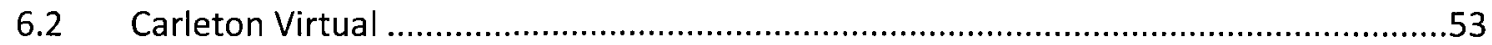

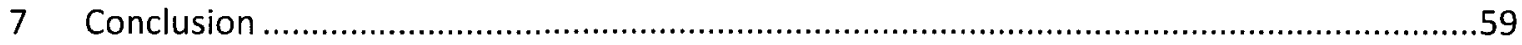

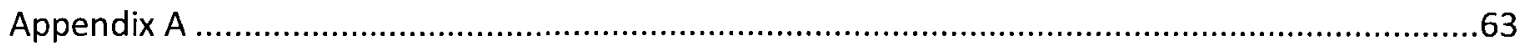

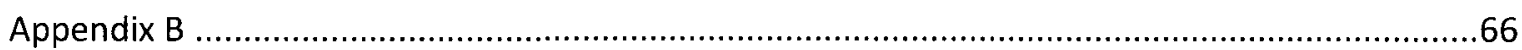

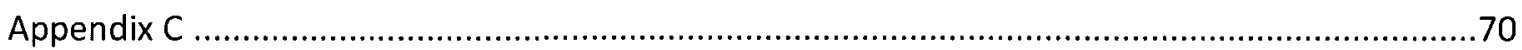




\section{Table of Figures}

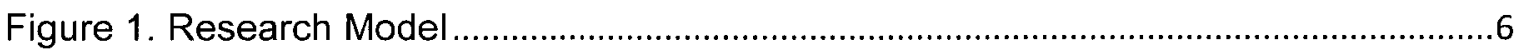

Figure 2. Basic Technology Acceptance Model..........................................................20

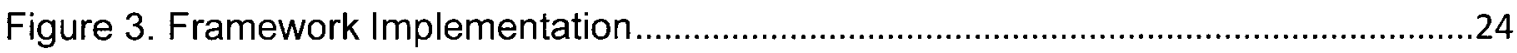

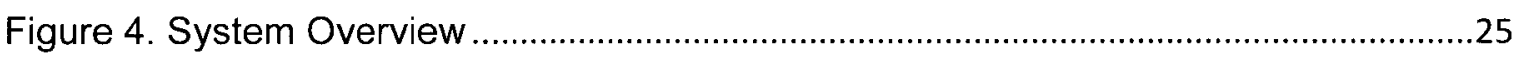

Figure 5. Participants Having a Discussion in the Atrium ............................................26

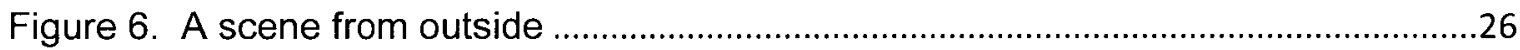

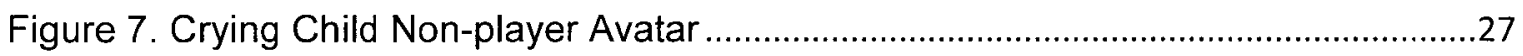

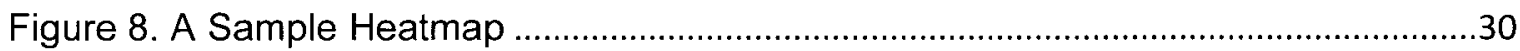

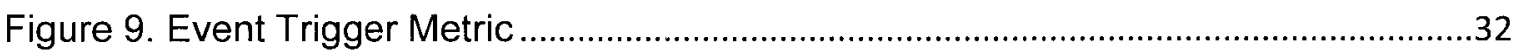

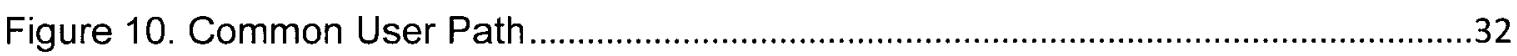

Figure 11. Student Indivudual Interview \& Student Group Interview..............................36

Figure 12. Virtual Simulation Ease of Use and Team Work Performance........................42

Figure 13. Face-to-face Simulation Ease of Use and Team Work Relationship: .............45

Figure 14. Third Simulation Ease of Use and Team Work Skills Relationship ................48

Figure 15. General Structure of the Carleton Virtual.....................................................54

Figure 16. A View from Quad Area ..............................................................................55

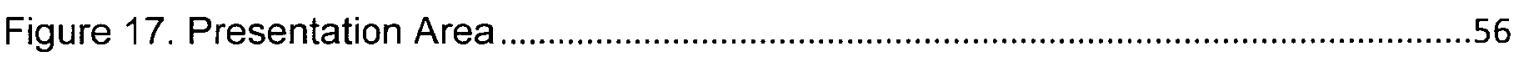

Figure 18. Carleton Virtual Archeological Excavation Site...........................................58 


\section{Table of Tables}

Table 1. Participant responses to virtual reality component of the workshop...................38

Table 2. Virtual Simulation Independent T-Test Analysis ..............................................41

Table 3. Virtual World Simulation TOSCE Analysis .......................................................41

Table 4. Initial Face-to-face Simulation Independent T-Test Analysis ............................43

Table 5. Initial Face-to-Face Simulation TOSCE Analysis...........................................44

Table 6. Final Face-to-Face Simulation Independent T-Test Analysis .............................46

Table 7. Final Face-to-Face Simulation TOSCE Analysis ............................................47

Table 8. Average Students Rating for 2D and 3D Archaeological Simulation ..................52 


\section{Introduction}

Virtual Teams (VTs), in which members use technology to interact with one another across geographic, organizational, and other boundaries, are becoming a common place in organizations (Gibson \& Cohen, 2003). One of the attribute of successful organization is being structured as a dynamic network based on the business need via using Information and Communication Technology (ICT). Virtual teams are one of the very important building blocks of this structure. (Powell et al., 2004)

Surveys also support the above view. The Wall Street Journal reports that more than half of companies with more than 5000 employees use virtual teams in 1999 (de Lisser, 1999). A survey done by the Gartner group found that more than $60 \%$ of professional employees work in virtual teams (Kanawattanachai \& Yoo, 2002). The growing prevalence of virtual teams is being attributed to a confluence of technological and organizational developments along with a range of business benefits associated with using these types of teams (Solomon, 2001).Recent studies also suggest that virtual teams are on the rise in a post-recession era (Bullock, Klein 2010). The study, "Virtual Work Environments in a Post-Recession Era," conducted on behalf of Brandman University by Forrester Consulting, revealed strong adoption of virtual teams, defined as a group of people working together from disparate locations on a specific project, with 40 percent of survey respondents saying that 40 percent or more of their company's employees work in virtual teams today, and more than half (56 percent) expect virtual teaming to increase in the next one to three years. The growing prevalence of virtual teams is being attributed to a confluence of technological and organizational developments along with a range of business benefits associated with using these types of teams (Solomon, 2001). 
Virtual teams can be composed of the best individuals for the task regardless of their physical or organizational location, thus enhancing the quality of decisions (Lipnack \& Stamps, 1999; Townsend, DeMarie \& Hendrickson, 1998). Further, to attract and retain employees, knowledge workers in particular, organizations are increasingly offering remote working options to their employees (Cascio, 2000). Interaction through a digital media is becoming commonplace within large organizations and it has been noted that in a typical global organization, approximately $20 \%$ of employees have not experienced a face to face interaction with their employer (Kharif, 2007). Overall, VTs provide an effective structural mechanism for handling the increased travel, time, coordination, and costs associated with bringing together geographically, temporally, and functionally dispersed employees to work on a common task.(Martins, 2004).

Virtual team members collaborate and communicate using digital media. Traditionally, Information and Communication Technology (ICT) tools such as websites, email and messaging systems, have contributed to the speed of communication and dissemination of information are used as digital media for virtual teams. However, their ability to support knowledge creation and assimilation is limited. Traditional ICT strips away the nonverbal cues that clarify messages, and do not provide the physical and linguistic "co-presence" that face-to-face communicators use to draw inferences about one another's knowledge (Roberts, 2003). Traditional ICT tools are also limited in their ability to simulate real-world experiences, critical for the assimilation of complex concepts.

Three-Dimensional Virtual Environments (3DVEs) are graphical environments resembling 3D spaces where users control computer-generated characters (avatars) that 
represent them, while interacting with the environment and other users, and possibly with computer-controlled characters (agents) using Artificial Intelligence (AI). 3DVEs can contribute to an educational and research system by facilitating communication, collaboration, and simulation. 3DVEs provide an electronic surrogate for face-to-face interaction and allow the creation of simulated environments and experiences otherwise not possible due to high cost, physical or logistics constraints. By providing a platform that closely resembles physical interaction, 3DVEs permit interaction with a computing environment and the work of other users, while creating the perception that one exists within the environment. Immersive virtual worlds are also being offered as a collaboration media for virtual teams. In the context of virtual world as a digital media for collaboration, this means that these platforms enable users to fulfill certain tasks, such as searching for or meeting people, more effectively (Roberts, 2003).

The study is performed in an immersive virtual environment on Cyworld, which is a web community site operated by SK communication (http://us.cyworld.com/) explores attitudinal and behavioural patterns when using Cyworld. Three main constructs identified in this study; perceived synchronicity, perceived involvement, and the users' flow experience. (Shin, 2008). These three variables are strongly related with Web2.0 features, such as user participation and feelings of co-presence (Shin, 2008).

When introducing a new collaboration and communication tool, it is important for the business leaders to be able to estimate the acceptance of the technology among team members, if possible before making a huge investment. Different models are suggested in the literature to estimate user acceptance and usage for a technology. 
Technology Acceptance Model (TAM) has come to be one of the most widely used models in industry in part because of its ease of understanding and simplicity (Venkatesh 2003). Perceived Ease of Use (PEU) is one of the constructs used by different user acceptance models as well as TAM (Venkatesh 2003). Perceived Ease of Use refers to "the degree to which a person believes that using a particular system would be free of effort". As noted in Venkatesh' study "User acceptance of information technology: Toward a unified view", Perceived Ease of Use is one of the influencers on an individual's attitude toward using the technology and thus ultimately relating to actual use. This relationship has been supported by other researches (Taylor \& Todd, 1995; see Sheppard et al., 1988 for a meta analysis of the intention-behaviour relationship). Although user acceptance models were used in the literature to predict user acceptance of the technology and a positive relationship is always assumed between behavioural intention of use and performance, this relations remains to be supported by more researches and identified as one of the most important directions for future research is to tie this mature stream of research into other established streams of work. (Venkatesh, 2003). 


\subsection{Objective}

The objective of this research was to study the relationship between perceived ease of use and individual team performance, and test the assumption that there is a positive relationship in a team performance context. The study presented here captures an investigation into the relationships between ease of use and team performance overall and over the following team skill performances:

- Communication: Communicates and expresses ideas in an assertive and respectful manner; uses communication strategies in an effective manner with others.

- Collaboration: Establishes collaborative relationships with others; promotes the integration of information and perspectives from others; ensures that appropriate information is shared with other providers.

- Conflict Management: Demonstrates active listening and is respectful of different perspectives and opinions from others; works with others to prevent and deal effectively with conflict.

- Team Functioning: Evaluates team function and dynamics; demonstrates shared leadership within the health care team that is appropriate to the situation; contributes effectively and meaningfully in interprofessional team discussions.

- Roles and Responsibilities: Describes one's own roles and responsibilities in a clear manner; describes the roles and responsibilities of other providers; shares best practice knowledge with others; accepts accountability for one's contributions. 


\section{Research Model}

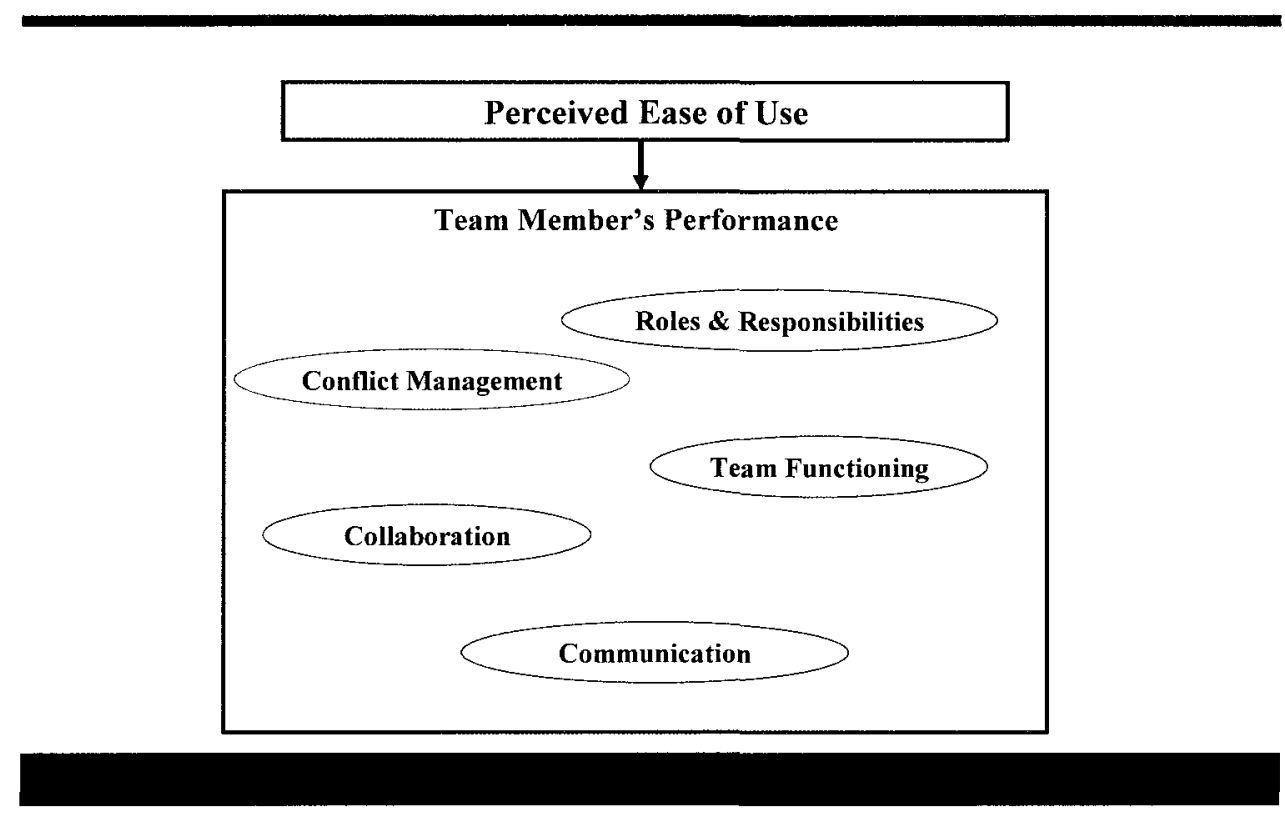

Figure 1. Research Model

The main question of this thesis is:

Is there a positive relationship between Perceived Ease of Use and virtual team performance?

We expect that individual at ease with underlying technology used for communication within virtual team perform better than those are not at ease. Thus, we hypothesize that: H1: There is a positive relationship between Perceived Ease of Use and virtual team performance

Further, we try to find supporting data for the following hypotheses:

H2: There is a positive relationship between Perceived Ease of Use and virtual team performance collaboration component

H3: There is a positive relationship between Perceived Ease of Use and virtual team performance communication component

H4: There is a positive relationship between Perceived Ease of Use and virtual team performance team functioning

H5: There is a positive relationship between Perceived Ease of Use and virtual team performance conflict management 


\subsection{Deliverables}

This study performed on phases and each phase had different deliverables:

- A requirement analysis and virtual world design documentation

- An immersive environment for the team skill development

- An analysis documentation on bets practices on deigning a virtual world for education purposes.

- User survey data and analysis of the data collected

- A model showing relationship between perceived ease of use (PEU) and team performance dimensions.

\subsection{Contributions}

There are three major contributions from this research that complement existing research in this field:

Virtual teams, effectiveness and performance: Several studies have observed that the level of technical experience of team members has an impact on the ability of a team to perform effectively and on individual satisfaction. Lack of both technical experience and the ability to troubleshoot associated problems has negative impacts on performance of the team and individual satisfaction (Kayworth \& Leidner, 2000; van Ryssen \& Godar, 2000, Powell et al,, 2004). This research contributes to virtual team and performance stream of research by providing data supporting this view and taking the existing research a step further by studying the impact on the team work performance dimensions. 
User Acceptance and Performance: Our second contribution is to the technology and user acceptance research stream. Technology and user acceptance of technology have been of interest to researchers over the last century, in both individual and organizational contexts. There has been significant growth in computer and information technologies in businesses and organizations. Westland and Clark reported that since the 1980's, approximately fifty percent of new capital investment in organizations has involved information technology (Westland \& Clark, 2000). Perceived ease of use has been one of the main constructs of user acceptance models that help us to predict the user acceptance of the technology and usage. It is always assumed that there is a positive relationship between intention of usage of the technology and user's performance. However, there is little research in the literature supporting this hypothesis. An important aspect of future research is to tie this model into other work streams, examining the association between user acceptance and organizational and individual usage outcomes. (Venkatesh et al., 2003). This research contributes to this stream of research by providing data supporting the assumption that there is a positive relationship between intention of usage of the technology and user's performance.

Design and development of 3DVE customized for educational tasks, demonstrating the abilities of virtual spaces: With the advances in e-Learning systems, the education community shows a growing interest in using online tools for educational purposes. The case studies presented in this study demonstrate how a 3D Virtual Environment can be used as a learning tool by providing a virtual space that (1) allows people in different locations to interact, (2) gives users access to facilities not available physically, (3) enables activities that are not possible in physical settings, and (4) offers a 
variety of observation and measurement tools for performance evaluation and improvement.

This research demonstrates these advantages through case studies that offer a framework for language learning for English as Second Language students and a simulated archaeological excavation site for History students, in the context of Carleton Virtual, a 3D virtual environment for Carleton University. Based on the results that show the advantages of using the virtual space as a learning environment, in Algonquin College for team work skill development we argue that Virtual Space can be a new framework for learning.

Following publications have been presented/submitted to internationals conferences and journals as the result of the study reported in this thesis:

- Nuket Nowlan, Eleanor Riesen, Michelle Morley, Ali Arya, and Nicholas Sauriol, "A Framework for an Immersive Learning Environment with Telemetrics and Simulation," published in Ubiquitous Learning: An International Journal, 2010

- Ali Arya, Peggy Hartwick, Shawn Graham, Nuket Nowlan, "Virtual Environment as a Learning Space: Two Case Studies, " presented in IETC-2011, Istanbul, Turkey. 2011 http://www.iet-c.net/

- Ali Arya, Nuket Nowlan, Nicholas Sauriol, "Data-driven Framework for an Online 3D Immersive Environment for Educational Applications," presented in EduLearn-10 - Barcelona, Spain, July 5-7, 2010.

- Nuket Savaskan Nowlan, Ali Arya, Eleanor Riesen, Michelle Morley, "The Effect of Perceived Ease of Use on Virtual Team Performance", to be presented in 
Ubiquitous Learning 2011, Berkeley, US, November 2011.

\section{http://q1 1.cgpublisher.com/proposals/75}

- Ali Arya, Peggy Hartwick, Shawn Graham, Nuket Nowlan, "Case Studies on the Use of Virtual Spaces for Education", Submitted to Journal of Interactive Media in Education, 2011

\subsection{Relevance}

There are at least four groups to whom this research may be relevant.

\section{Business Leaders}

The first relevant group comprises business leaders who are trying to increase the efficiency of a company's virtual teams. This research provides insight to them on relationships between collaboration technology and team performance.

Increasing team efficiency in any organization is one of the main objectives of any business leader. Thus, this research is relevant to business leaders in identifying the problems for underperforming teams or in choosing the right technology for communication and collaboration for their organization. Research presented in this thesis provides valuable insight.

\section{Communication and Collaboration Technology Designers and Entrepreneurs}

Ironically, users and the main intended usage of the technology can be forgotten by the designers and business leaders during the design phase due to many reasons. This research provides an insight about the importance of technology design and the importance of user interface being easy to use and compatible with the interface user is familiar already. 


\section{Team Leaders}

This research provides a valuable insight to team leaders, especially if they are having conflict management issues within the team. Making sure that the technology in use for communication and collaboration is well mastered by each member of the team might be an area to focus on to resolve the issue.

\section{Researchers}

There are many aspects for researchers to study in terms of the relationship between the technology in use and knowledge workers' performance. Providing data supporting the theory that there is a positive relationship between ease of use and team performance will provide an insight to researchers within the relevant context.

\section{Educators}

This research demonstrates the advantages of using immersive virtual environments for education. Through case studies, this study offers valuable insight on creating custom virtual spaces for education purposes.

\subsection{Limitations}

This research was performed within a very short time period with participants recently graduated from the college.

We admit that a long-term research with teams having a history of working together would give more reliable results in terms of team functioning.

It would be also more desirable to be able to observe team functioning for a longer term to understand the long term relationship of the technology and individuals performance. 


\section{Literature review}

\subsection{Virtual Teams: Advantages \& Challenges}

Virtual collaboration and working as a team, a group of people working together as a team to accomplish a shared objective, is becoming a common business structure (Bullock, Klein 2010). Today's distributed work force demands people interact, communicate and collaborate with a person physically located 100 miles away. Thus, collaboration and learning are becoming a main focus of organizational researchers. Collaboration is a process often required by researchers to solve problem, innovate or make discoveries (Schrage, 1990). Collaboration is an important process as it allows results of greater value than can be achieved by solely communication or teamwork (Schrage, 1990). While teamwork is defined as a concept of people working together toward a common goal, collaboration is defined as a recursive intellectual endeavour, creative in nature in the teamwork and collaboration guide published by Galileo Educational Network (Galileo Educational Network, 2008). Therefore, team collaboration may be defined as the sharing of ideas and open and direct communication enabling conflict resolution and support for research and innovation (Aram \& Morgan, 1976).

In the development of knowledge workers' potential, it is essential to encourage their shared interests, common values and mutually satisfying solutions (Quinn et al., 1996). To facilitate effective team building, collaborative learning is required which is dependent upon developing a cooperative relationship among team members. Key to this is the development of personal familiarity, intimacy, trust among team members, and 
ensuring that they respect each other's opinions (Comstock \& Fox, 1995). Individuals tend to wish to reduce or resolve conflict through compliance or compromise. When working with group dynamics however, it is important to encourage members to recognize and respect diversity and use it to create and innovate. This has been termed "breakthrough thinking". When a team learns how to do this, the optimum interdependence found in high performance teams can be achieved (Holton, 2001).

Johnson et al. point out various reasons why virtual teams are extremely useful for organizations (2001). They state that using virtual teams gives members a more flexible work schedule, thus providing more time for family and other interests. This is very important, because it helps increase an employee's happiness, which in turn increases their productivity (Johnson et al., 2001). According to Johnson et al., other important justifications for using virtual teams are that it:

- Creates and disperses improved business processes across organizations

- Supports cross-functional and cross-divisional interaction

- Saves time and money in daily transportation to and from work

These advantages have associated costs. According to a 2010 survey by RW3, 80 percent of corporate managers work virtually at least part of the time. But a surprising proportion of virtual team members - 40 percent - believes their groups are underperforming (RW3, 2010, http://rw-3.com/VTSReportv7.pdf). In an article discussing the intricacies of virtual teams, Kirkman et al. state that there are five important challenges to implementing successful virtual teams: building trust within 
virtual teams, maximizing process gains and minimizing process losses, overcoming feelings of isolation and detachment associated with virtual teamwork, balancing technical interpersonal skills among virtual team members, and assessment and recognition of virtual team performance (Kirkman et al., 2002).

The first challenge focuses on trust issues that can occur when working with a virtual team. However, while it is commonly accepted that it is hard to develop trust in a virtual environment as many of the ways we use to establish trust in a face to face team are sometimes absent from virtual teams; Kirkman, et al. found that the qualities of reliability, consistency, and responsiveness between team members and customers are important in the development of trust in virtual teams. This has been described as abilitybased or task-based trust (Kirkman et al., 2002). Trust is directly related with the productivity as productivity in a team conducting knowledge work is related directly to how team members regard each other, the projects they select to work on and associated tools to complete their work (Pasmore \& Purser, 1993).

The second challenge is concerned with how well virtual teams can maximize process gains and reduces process losses. Process gains refer to positive synergy, while process losses refer to negative synergy. It has been widely believed that virtual interactions produce more process losses than gains, because they lack face-to-face interaction. However, Kirkman et al. state that visualization of a team member's gender or race/ethnicity may reduce team integration and negatively affect the performance of highly diverse virtual teams (Kirkman et al., 2002). Also, they point out that electronic collaboration in virtual teams may result in the participation of greater numbers of minorities. This may indeed result in enhanced integration of minorities into team 
projects (Kirkman et al., 2002). Therefore, virtual teams can replace, if not improve on, the synergy that can be developed through face-to-face interaction.

The third challenge that Kirkman et al. list states that feelings of isolation and detachment have been linked to working with virtual teams. It has been argued that feelings of isolation and detachment due to a lack of face to face interaction may result in a loss of productivity in virtual teams (Kirkman et al., 2002). These feelings can be counteracted or avoided by focusing on the social and psychological needs of employees. For example, psychological testing may identify and address social needs of team members. Comprehensive job previews may help to identify and further shape the expectations of prospective employees. Further, concentration on increasing both virtual team building and client contact may also contribute to meeting social needs. The ability of team leaders to reach out to more isolated team members may also address social needs (Kirkman et al., 2002). Therefore, while feelings of isolation and detachment are problematic, they can be effectively reduced to provide better experiences for all members involved.

The fourth challenge is how to balance technical and interpersonal skills between members of a virtual team. Conventionally, it has been viewed that team members should be selected for their technical skills, because virtual teams require people to use digital technology, which can be complex and difficult to learn. However, Kirkman et al. find that interpersonal skills are as equally important as technical ones (Kirkman et al., 2002). They reported that it is important to recruit and retain team members who have a good balance of both interpersonal and technical skills. Even though communications take place in a virtual environment or through various communication technologies, there is 
still a need for employees to have strong skills in relaying their ideas in an understandable manner.

The final challenge is how the performance of virtual teams should be assessed and recognized. It has commonly been accepted that if one is unable to physically monitor their subordinates, then they cannot readily assess their performance. However, Kirkman, et al. states that this is untrue, because a balanced scorecard approach can be used to successfully measure a team's effectiveness. They suggest that monitoring performance data of team members allows for recognizing and rewarding performance both of the team and individuals members. This approach may also help to identify the need for training programs or other mentoring mechanisms to assist virtual teams or individual members (Kirkman et al., 2002)." Using these techniques can help identify employees and teams that are being effective, while not having to monitor them in a physical sense.

\subsection{Virtual Teams and interpersonal relationships}

Research regarding interpersonal processes in virtual teams has primarily focused on conflict, inappropriate behaviour (eg. swearing), and the lack of formality in communication, interpersonal trust, and group cohesiveness. Conflict has been reported to result in better group decisions/conclusions since more alternatives are discussed prior to making a final decision (Jehn \& Mannix, 2001). In fact, more conflict is likely to occur in virtual teams than in face to face discussion groups (Mortensen \& Hinds, 2001). Several factors may influence conflict in virtual teams. For example, a feeling of having a group identity may reduce the amount of conflict a virtual team experiences (Mortensen 
\& Hinds, 2001). Further, female team members were found to more easily resolve conflict than males in a study examining 29 virtual student teams (Lind, 1999). In addition, the ability of virtual teams to handle conflict has been reported to depend upon how well the team used virtual teaming technology to address conflict (Poole et al., 1991). Studies have also demonstrated that internal conflict could be effectively managed using competitive or collaborative conflict management styles (Montoya-Weiss et al., 2001; Paul et al., 2004). The study by Paul et al. found that collaborative conflict management had a positive influence on satisfaction, perceived decision quality, and participation.

Working in a virtual context has also been reported to support more uninhibited behaviour than in face to face interactions, with activities such as swearing, insults and name calling being more frequent (Siegel et al., 1986). In addition, greater levels of selfabsorption were also apparent in the virtual context (Sproull \& Kiesler, 1986). It has been reported that this may result from composition of the virtual team as men are more likely to demonstrate more argumentative and coarse language than women in virtual teams (Savicki et al., 1996).

It has been suggested that the media used for communication by virtual teams is lower in richness and synchronicity this discourage team members having less informal or non-task related communication. For example, it has been reported that less discussion of personal matters unrelated to the team's work occurs in virtual teams than in face to face groups (Lebie et al., 1996). It has been suggested that this may result from less readily available contextual information in virtual teams. Virtual team members therefore need to seek more information in order to comprehend the complete meaning of a communication (Cramton, 2001). It is therefore not surprising that highly productive 
virtual teams are able to use informal ways of communication more often than less productive virtual teams (Saphiere, 1996). A significant influence on the degree that informal communication is exchanged is the virtual team's belief in interactions in the future. This may also have more influence than the medium of communication (Walther, 1994). In another report of Computer Mediated Collaboration (CMC) groups, it was found that informal communication improved over time (Chidambaram, 1996). A study of $\mathrm{CMC}$ dyads demonstrated that members often asked deeper, more direct and intimate questions of each other than in face to face interactions. Indeed, in face to face meetings, members were more likely to ask more peripheral questions. Members of CMC dyads also had higher levels of self disclosure than was demonstrated in face to face interactions (Tidwell \& Walther, 2002).

Businesses expect virtual worlds to enrich electronic interaction by offering the visual, aural, and spatial dimensions lacking in the lean channels that are commonly used today (Kharif,2007). Most importantly, businesses would like to know if virtual worlds enable more effective collaboration in virtual teams than the virtual teams using more traditional communication tools carrying less personal cues, such as emails or text based chat. (Kharif,2007). In an attempt to answer the many questions that potential clients have for using virtual world technologies, there have been various studies on how virtual interactions are perceived by users and how they affect them. One such study is by Fetscherin and Lattemann on user acceptance of virtual worlds. They posit that interaction in a 3D format along with a voice over Internet Protocol (IP) plays a critical role in acceptance of virtual worlds by both users and technology (Fetscherin \& Lattemann, 2008). Analyzing their data, they also concluded that the perceived value of 
communication, cooperation communication channels, and behavioral intention to use the system was perceived ease of use (Fetscherin \& Lattemann, 2008). Finally, for application in corporate or business environments, they argue that business models are required to provide value propositions to users that are both clear and attractive. Importantly, community building elements should be addressed such as communication, collaboration and cooperation. This will enable virtual worlds to become another mechanism to interact with customers.

\subsection{Technology \& User Acceptance}

Several studies have observed that the level of technical experience of team members has an impact on the ability of a team to perform effectively and on individual satisfaction. Lack of both technical experience and the ability to troubleshoot associated problems has negative impacts on performance of the team and individual satisfaction (Kayworth \& Leidner, 2000; van Ryssen \& Godar, 2000, Powell et al., 2004)

Technology and user acceptance of technology have been of interest to researchers over the last century, in both individual and organizational contexts. There has been significant growth in computer and information technologies in businesses and organizations. Westland and Clark reported that since the 1980's, approximately fifty percent of new capital investment in organizations has involved information technology (Westland \& Clark, 2000). However, for continuing productivity, staff must accept and use the technology. In the current literature on information technology, explaining the acceptance of technology by users has been described as one of the most "mature" areas 
of research (Hu et al., 1999). Several theoretical models in this area have been proposed involving information systems, sociology and psychology to describe over forty percent of the variance in individual intention to use technology (Davis et al. 1989; Taylor \& Todd 1995; Venkatesh \& Davis 2000; Venkatesh et al.,2003).

Venkatesh et al. performed research on 8 different technology acceptance models and developed a unified model (Venkatesh et al., 2003). The following model is given as the basic concept of a user acceptance model.

\section{Theoretical Framework;} User Acceptance Models

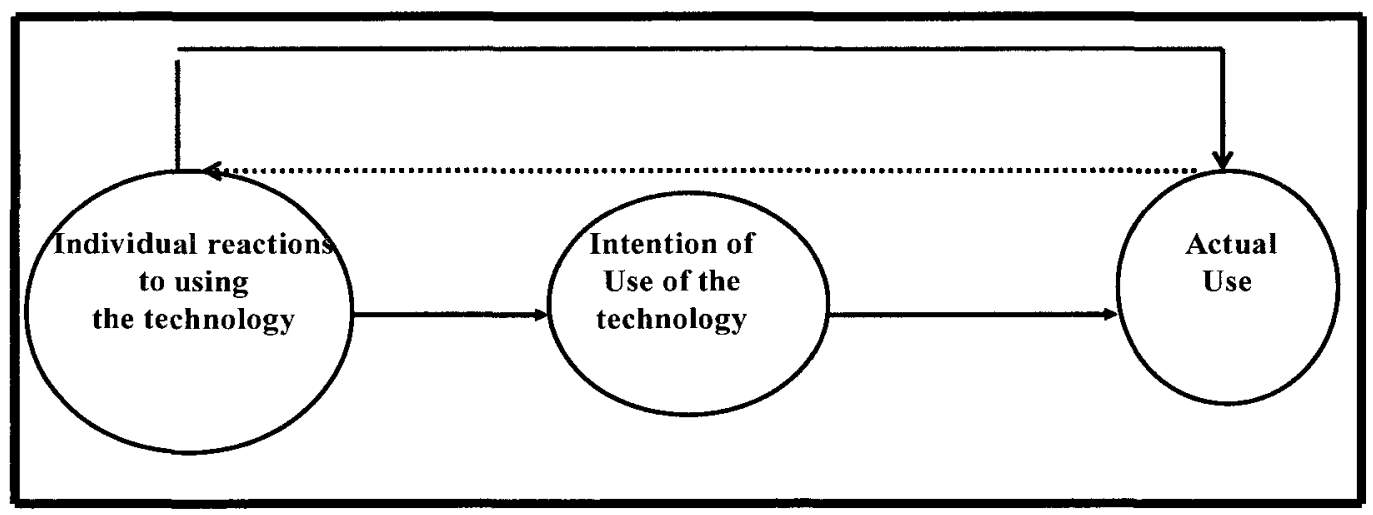

Figure 2. Basic Technology Acceptance Model

Technology Acceptance Model (TAM) is tailored to Information system contexts and was designed to aid in the prediction of information technology acceptance and usage in the workplace. TAM has been widely applied to diverse types of technologies and users and its constructs are defined as following: 
Perceived Usefulness: The perceived usefulness is the degree to which a person believes that using a particular system would enhance his or her job performance (Davis,1989).

Perceived Ease of Use: The perceived ease of use is the degree to which a person believes that using a particular system would be free of effort (Davis, 1989; Venkatesh et al., 2003).

TAM helps us to predict the user intention of usage and it is always assumed that there is a positive relationship between intention of usage of the technology and user's performance. However, there is little research in the literature supporting this hypothesis. An important aspect of future research is to tie this model into other work streams, examining the association between user acceptance and organizational and individual usage outcomes. For example, it remains to be determined whether usage will produce positive outcomes. This unified model may provide a useful tool for examining research questions into the long and short term effects of information technology implementation on work related outcomes such as productivity, organizational commitment and job satisfaction (Venkatesh et al., 2003). 


\section{Research Method}

\subsection{Building a Virtual World for Team work}

This study has mainly been performed within the framework of a project called Persephone, which is an immersive virtual environment. Within the overall context of the study another virtual environment called Carleton Virtual has also been designed and implemented keeping in mind the best practises learned from Persephone.

These types of environments offer the possibility of engaging simulation-based training, but for multiple geographically-dispersed learners. Perhaps the most famous multiple-user immersive platform is "Second Life" (www.secondlife.com), which is a 3D virtual world that has been widely used for social, educational, and commercial purposes. Other examples include "Active Worlds" (www.activeworlds.com), Twinity (www.twinity.com) and instant messaging virtual universe (IMVU) (www.imvu.com). By focusing on Persephone and the members that took part in the environment, the connections between team performance and perceived ease of use can be better understood.

Before an in-depth analysis of Persephone can be detailed, it is important to know the intricate details of the environment in question. The virtual environment and the course content that made up this study represent a pilot project that was designed as a development and testing phase for a 6-week long course in inter-professional collaboration at Algonquin College in Ottawa, Canada. The pilot project was a two-day workshop that took place in the spring of 2009 , the objective of which was to improve the communication skills and inter-professional competence of participants. 
The virtual environment appeared to each user as a campus with a series of buildings that avatars could enter, each connected by pathways amid open grass-covered lawns. Users moved their avatars through the virtual environment using basic keyboard commands and performed basic physical movements (e.g., shaking hands) using an onscreen menu. Each user could see the virtual environment from the point of view of their avatar or as a $3^{\text {rd }}$ person.

The different "areas" of the virtual environment were controlled to define which avatars had access to specific locations within the virtual environment. This allowed for private meetings and restricted access to certain locations.

The virtual environment was created using the platform Web.Alive ${ }^{\mathrm{TM}}$. The content of the virtual environment was a set of 3D assets generated using standard software tools and environmental controls such as events, triggers, scripts, and volumes. These were defined using the Web.Alive ${ }^{\mathrm{TM}}$ editor, which also served as the tool to put together all of the assets. Web.Alive ${ }^{\mathrm{TM}}$ is based on the Unreal Engine by Epic Games (www.unrealtechnology.com) and supports a variety of different asset types. Figure 3 shows the framework for the implementation. 


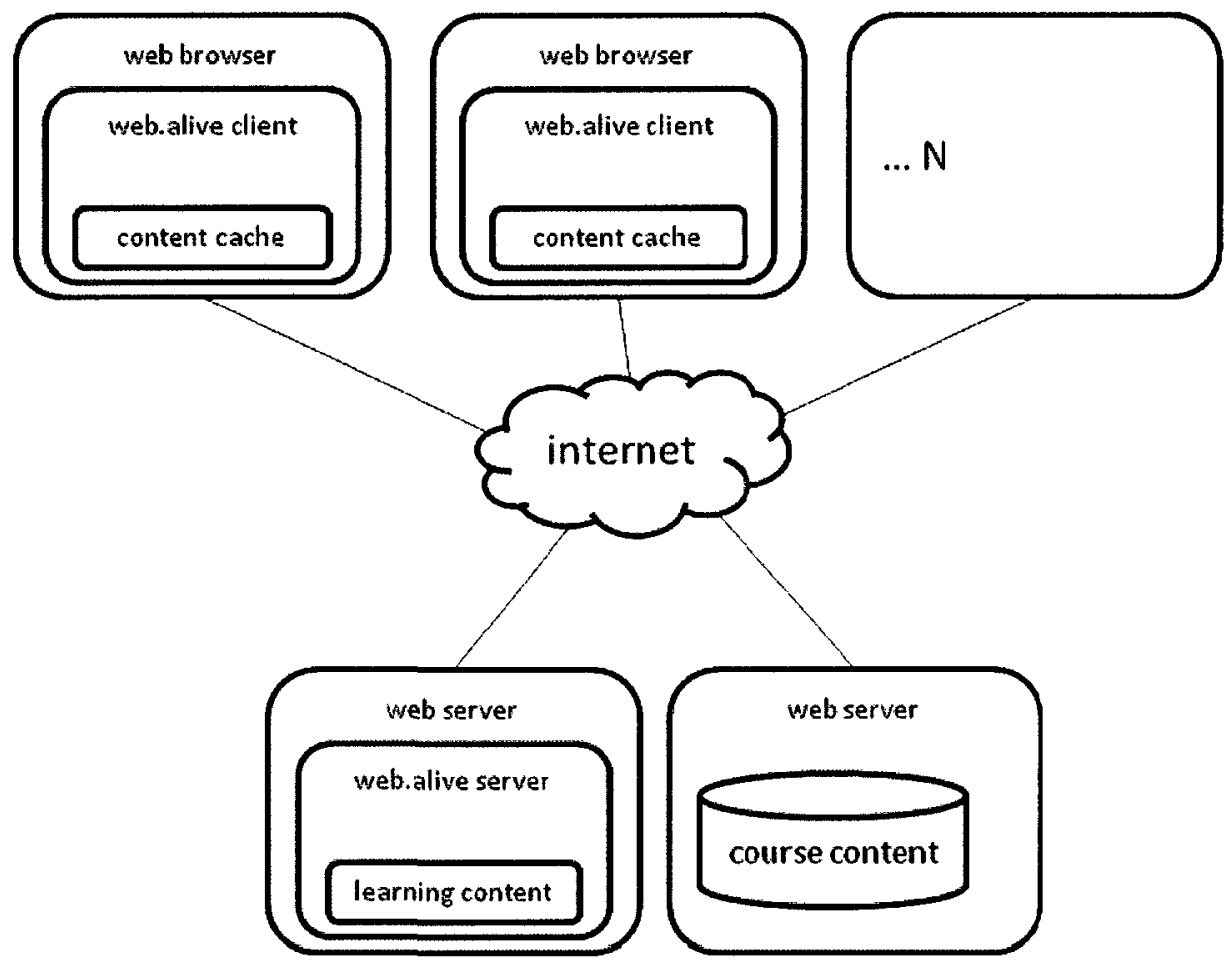

Figure 3. Framework Implementation

The implementation of this solution is broken down into three sub-sections: content, telemetrics, integration and deployment. A pipeline to content creation is presented. Content in this case is a suite of $3 \mathrm{D}$ assets assembled into a $3 \mathrm{D}$ environment. An overview of the telemetric instrumentation and data collection methodology is provided to give insight into current and future potential of the system. Integration of both current and developed specifically immersive technology methodologies with existing pedagogical tools is provided to help understand the end state vision of this project. An overview of the deployment of the solution is also provided to give a sense of how this solution is used and maintained. 


\subsection{System Overview}

Figure 4 shows the general structure of Persephone, including spaces for lectures, simulations, and social interaction. Figure 5 and Figure 6 capture the views of the environment that was created. Figure 5 shows the lecture hall while Figure 6 is an outdoor view showing three item types: Item 1 in the figure is one of five instances of a bungalow used by students for situation simulation in context. Item 2 in the figure is one of a suite of offices placed throughout the environment to indicate the different organizations represented (nursing, policing, paramedics, fire and rescue, etc.) and contains virtual office and collaboration space. The final item is an open concept collaboration space with tools such as a slide and document sharing surface as well as a synchronised web collaboration surface.

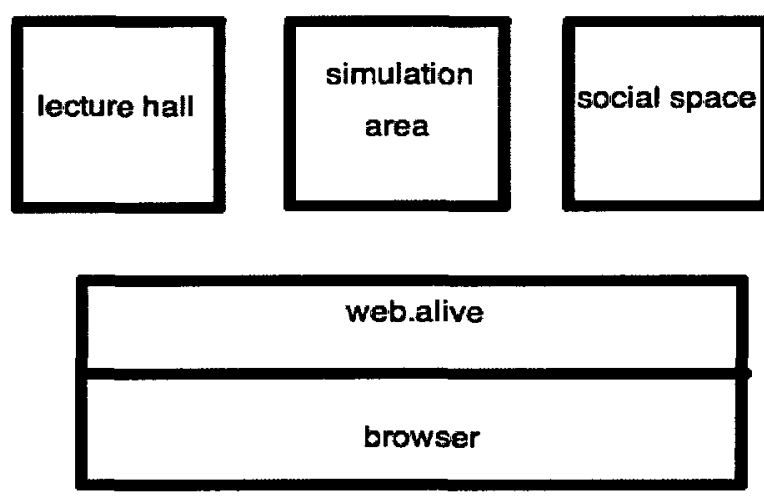

\section{Figure 4. System Overview}

Due to the very nature of the simulated $3 \mathrm{D}$ environment, it can not be fully represented in images in this document. However, select images taken from key vantage points are presented as in Figure 6. 


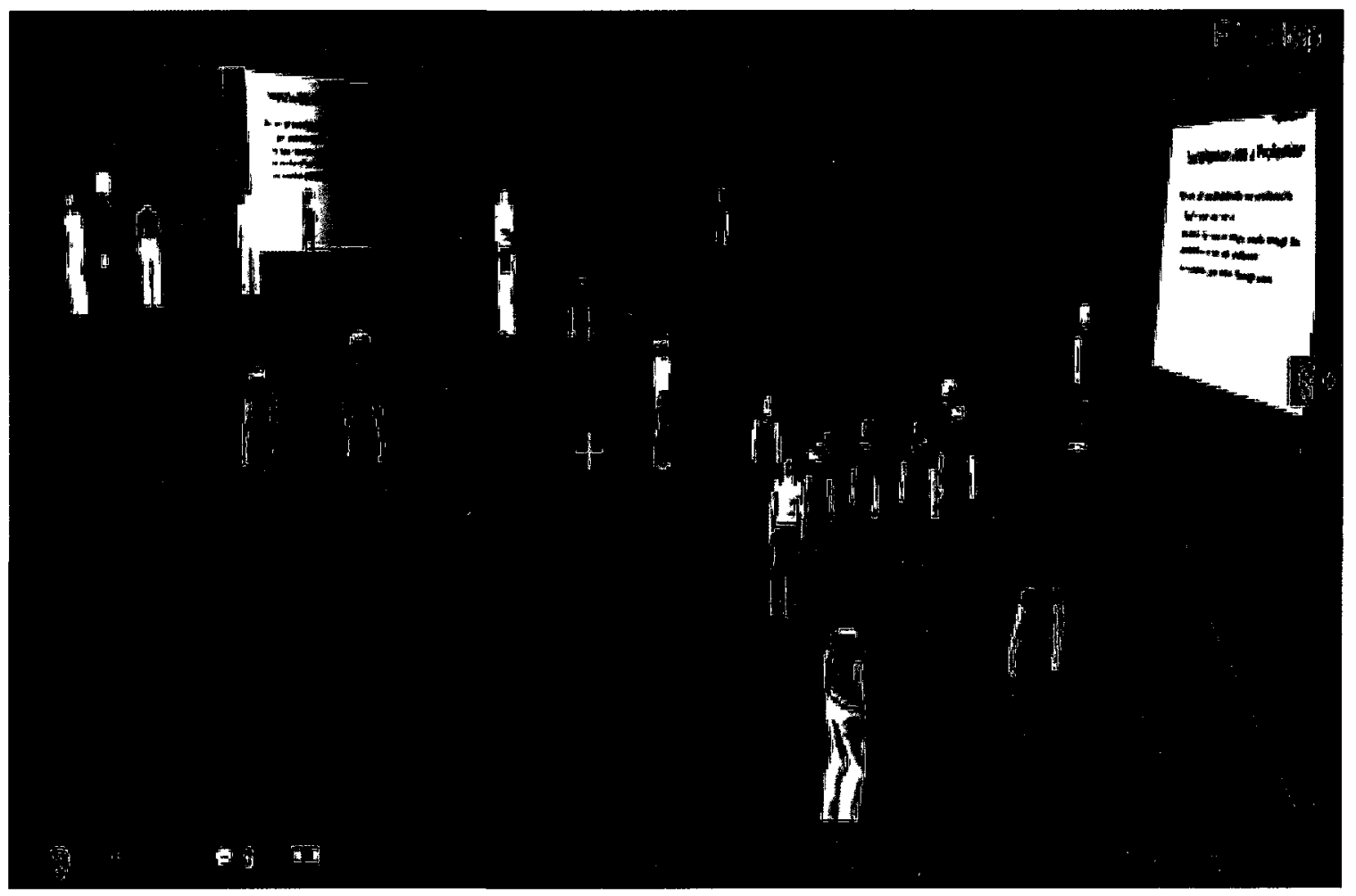

Figure 5. Participants Having a Discussion in the Atrium

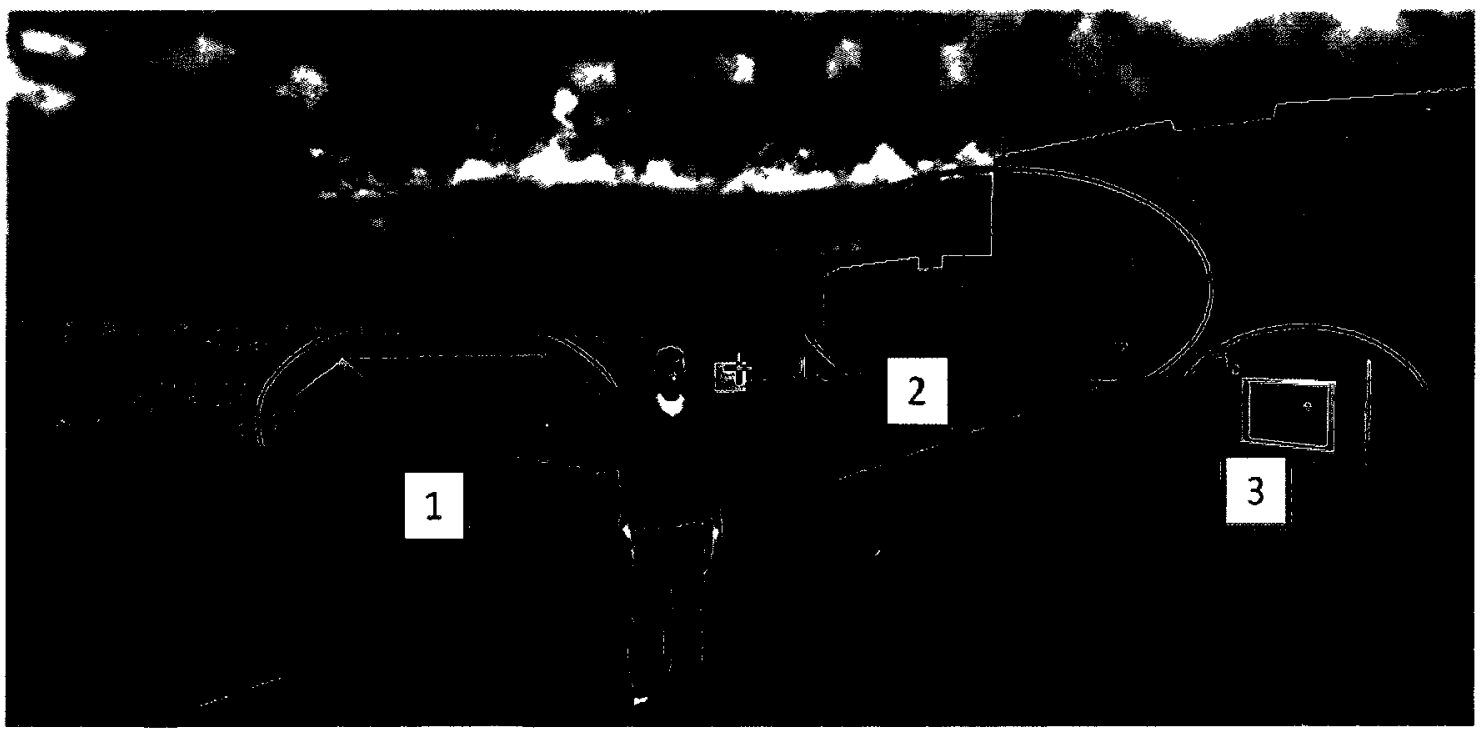

Figure 6. A scene from outside

Figure 7 shows the non-player child avatar planted in the environment to play the crying child role during the simulation. 


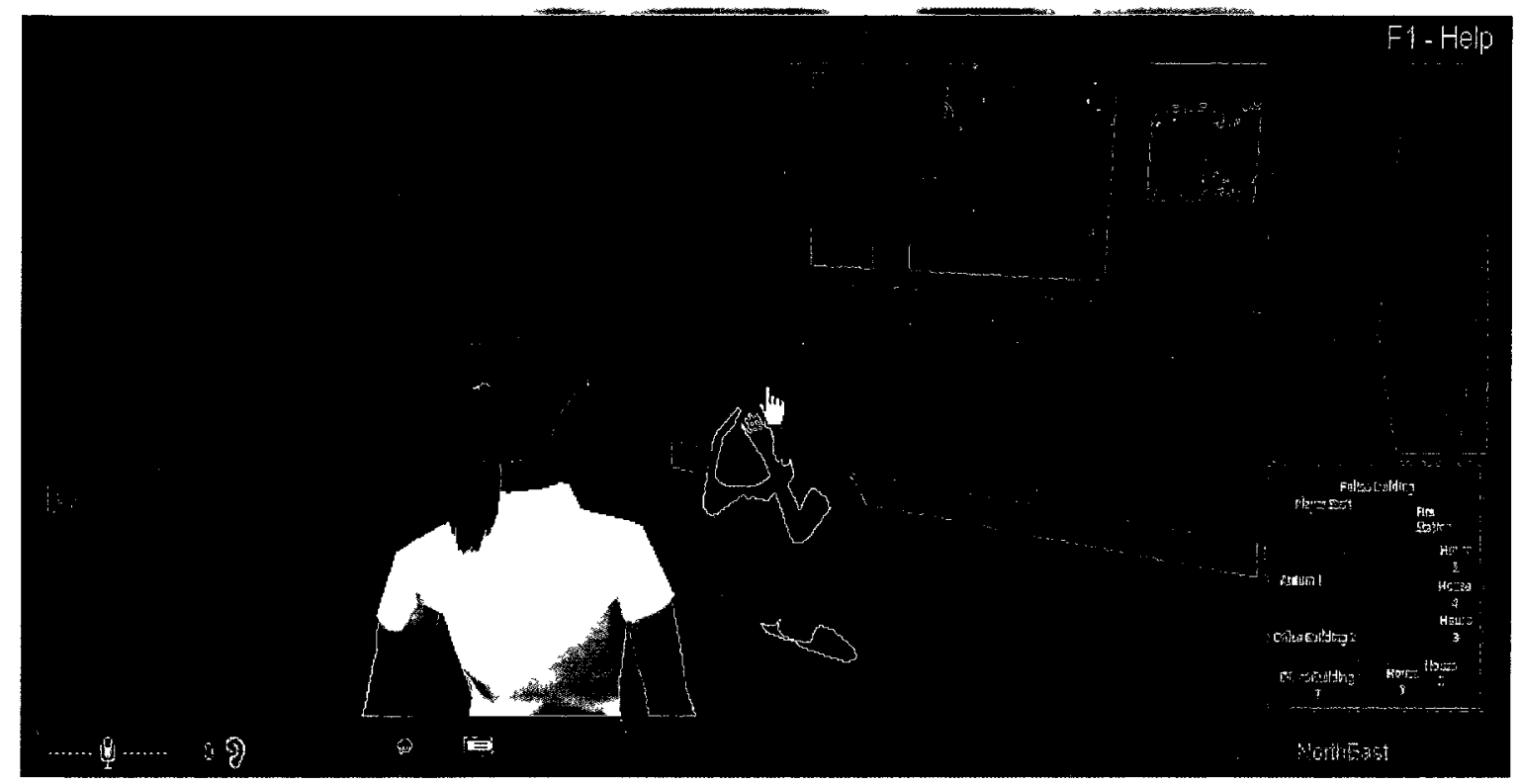

Figure 7. Crying Child Non-player Avatar

\subsection{Research Data Collection}

A pilot course is conducted for this study and following methods have been employed to collect the research data.
i) Simulations Recording
ii) Student Indivudual Interview
iii) Student Group Interviews
iv) Participants Survey
v) Performace Evaluations
vi) Telemetrices

The pilot course used to gather data in this research was delivered in the following order: 
- $\quad$ Pre-test knowledge test applied

- $\quad$ Real life scenario role play performed

- Discussion and debriefing on scenario

- Virtual World learning exercise

- Media presentation in the virtual environment: Understanding inter-professional education and communication

- Team communication activity in small groups in Virtual Reality

- Debrief and discussion in person

- Media presentation in the virtual environment(2): Understanding inter-professional education and communication with four professional profiles

- Virtual World scenario and role play performed

- Individual group leaders to facilitate debrief and discussion of reaction to scenario role play in virtual reality

- Real life scenario and role play

- Debriefing and feedback on role playing, use of technology and using virtual reality environment

- Pilot evaluation

Please note that participants' performance evaluated over dimensions that are defined within Team Observed Structure Clinical Encounter tool kit developed by 
McMaster and Ottawa University. The TOSCE tool was developed and validated for use as an assessment of interprofessional team competencies in primary care.

With funding support from the Ontario Ministry of Health and Long Term Care (HealthForceOntario grant), the McMaster-Ottawa team have created this TOSCE Tool Kit to enable interprofessional primary care teams to assess and improve their collaboration skills. Please refer to http://hhs.mcmaster.ca/tosce/en/index.html site for more information on TOSCE tool.

The evaluation dimension (Observer Check List) is provided in Appendix B for reference purposes. The figure below represents the model used in this research project.

\subsection{Telemetrics}

In selecting the web.alive tool from Avaya, the project gained access to a sophisticated and verbose logging system as well as a preconfigured set of analytic data and tools. In addition, the raw data affords the future potential of immersive learning focused analytics to help increase the overall effectiveness of education both within virtual environments and in real classrooms.

Data is collected by the system on both the server as well as the client. For privacy reasons, the data collected on the server is limited to data which is typically collected over the World Wide Web today such as source Internet Protocol (IP) address, user supplied name and action performed. On the client side, detailed logs are collected about encounters that occur within the environment - from individuals walking within listening radius of each other (an encounter) to two or more individuals speaking to each other within listening radius at the same time (a conversation). 
The logs are collected in both cases in a format consistent with the standard World Wide Web Consortium (W3C) logging format. In addition, the specific environment or content that was produced for this pilot was outfitted and configured to optimally gather useful data. For example, the environment is sub-divided into volumes or areas where the users can navigate to and from - entering and leaving each volume triggers a $\log$ (e.g. user entered classroom 2). Further, specific triggers were placed within the environment using built-in tools from web.alive such as stare triggers which initiate a $\log$ when a user places their cursor over an object (such as a slide presentation) for more than three seconds.

For example, using the tool we are able to observe (see Figure 12) the influence of conversation on active duration within the environment. As indicated by the graph, those users who did not actively participate in conversation within the environment during the pilot window were far more likely to idle or leave the environment. This is an excellent indicator of the importance of encouraging user participation in conversation during learning sessions.

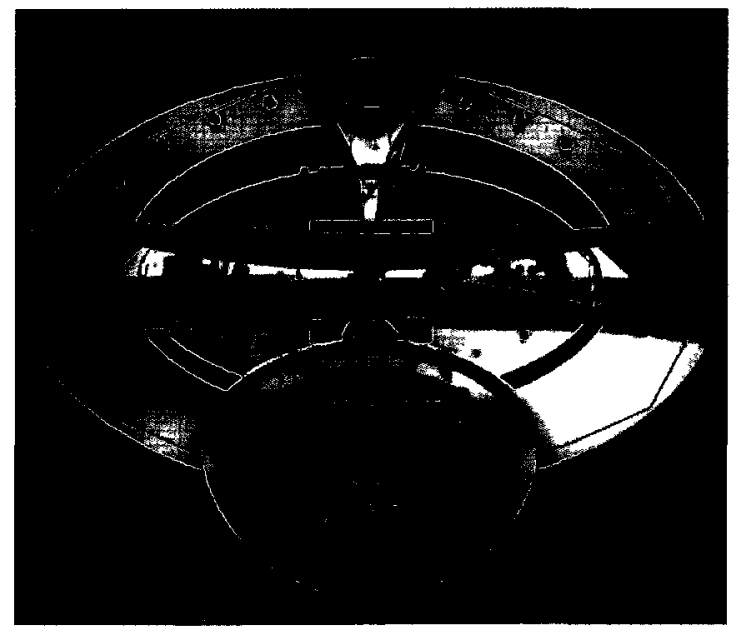

Figure 8. A Sample Heatmap 
In Figure 12 we can also see the distribution of logins to the environment both daily and hourly. What is most important to note from this data is that students not only entered the environment for the specific pilot, but also entered and spent time at other points, likely to collaborate with others and practice their simulations. Other analysis available affords us the possibility of identifying those that were most active in encouraging participation from others, the most popular actions and locations within the environment and more.

Further analysis of this data, including more advanced metrics such as calculations of the efficacy of any given media element (slide, video, web site, etc.) within the environment and overall effectiveness of different media types on student participation (are students more likely to become vocal after a slide presentation or a prerecorded video) are all possible and will be performed as more data is accumulated from the environment by using event trigger metric and common path metric. 
Trigger Misage

\begin{tabular}{|c|c|}
\hline LnuTigh & Laobothinulise \\
\hline 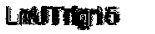 & Leatomathe \\
\hline LnUTitgro & 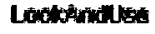 \\
\hline Lritumigita & 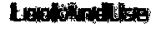 \\
\hline LศIJ Mg: & Lontoulnuluse \\
\hline$T$ Thatert & Thature \\
\hline LfuThigt2 & Locisumentes \\
\hline Thasme & Trage \\
\hline Stannerighet & Share \\
\hline 7ngens & 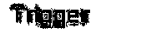 \\
\hline StareTing & Stare \\
\hline Lmuminger & 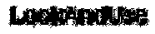 \\
\hline ganting70 & stare \\
\hline 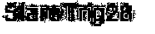 & Shat: \\
\hline Lnurting & Lackmatullase \\
\hline 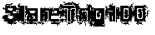 & Bfare \\
\hline Lfolutiged & Lenolonase \\
\hline Lumberta & 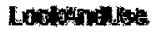 \\
\hline Stantivg & Stant \\
\hline 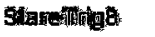 & swant \\
\hline StaneTrigti & Stane \\
\hline staretritage & Stere \\
\hline staneTry & gare \\
\hline 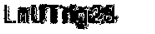 & 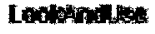 \\
\hline Shantrige2 & Stare \\
\hline
\end{tabular}

Top 20 Tropers

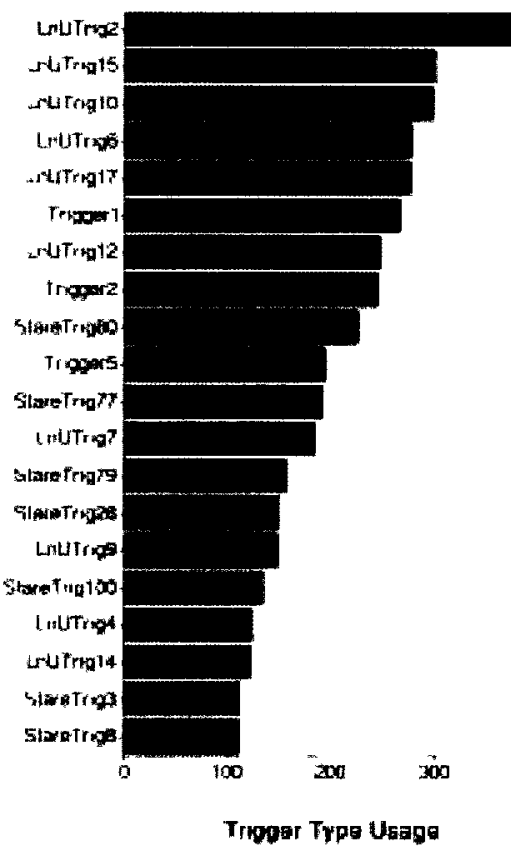

Figure 9. Event Trigger Metric

\section{Common User Paths}

pa

Persephone $\rightarrow$ NorthWest $\rightarrow$ NorthEast

Persephome $\rightarrow$ Norttawest $\rightarrow$ Apaptantheatre Hiall

Amphtheatre Hall-> NorthWest $>$ Persephone

Persêphone->Nonthwest- $\rightarrow$ SowitinNest

NorthEast->SouthEast->Persephone

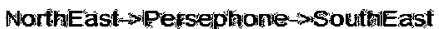

Northwest->Persephone->Coliaboration Area 2

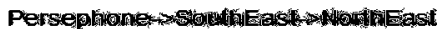

NorthWest-> Southwest->Persephone

NorthEast $\rightarrow$ North West $\rightarrow$ Perseplione

Collaboration Area 2-> Persephone $\rightarrow$ NorthWest

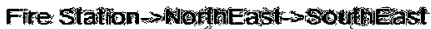

NorthWest $\rightarrow$ NorthEast $\rightarrow$ Fire Station

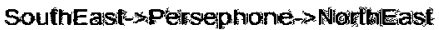

NorthWwest->Amphitheatre Halli->Persephone

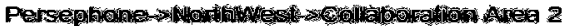

Collaboration Area $2>$ NorthWest->Persephone

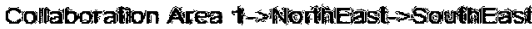

Persephone->NortmWest- $>$ NorthEast $\rightarrow$ Fire Station

Colllabonadion Area $5 \rightarrow$ Siouthitiast $\rightarrow$ Perseplinome

SouthEast- $\rightarrow$ NorthEast- $\rightarrow$ Fire Station

Northwest-s-NorthEast->Persephone

$\begin{array}{cc}299 & 52 \\ 166 & 29 \\ 147 & 25 \\ 144 & 25 \\ 142 & 24 \\ 141 & 24 \\ 135 & 23 \\ 132 & 23 \\ 131 & 23 \\ 127 & 22 \\ 120 & 21 \\ 109 & 19 \\ 108 & 18 \\ 106 & 18 \\ 102 & 17 \\ 96 & 16 \\ 95 & 16 \\ 93 & 16 \\ 88 & 15 \\ 86 & 15 \\ 84 & 14 \\ 82 & 14\end{array}$

Figure 10. Common User Path 


\subsection{Analysis tool}

The SPSS analyzing tool was used for determining the relationship between participants' performance and ease of use. SPSS (originally, Statistical Package for the Social Sciences) was released in its first version in 1968. SPSS is among the most widely used programs for statistical analysis in social science. It is used by market researchers, health researchers, survey companies, government, education researchers, marketing organizations and others. The original SPSS manual (Nie, Bent \& Hull, 1970) has been described as one of "sociology's most influential books" (Wellman, 1998). In addition to statistical analysis, data management (case selection, file reshaping, creating derived data) and data documentation (a metadata dictionary is stored in the data file) are features of the base software.

\subsection{Research Method}

Research reported in this paper uses following data to test the research hypotheses:

a. Second immersive virtual world performance recording for performance assessment.

b. Participants survey response on the following question:

How would you rate the ease of navigating within the virtual reality environment of this course?

$\begin{array}{lllll}\text { Excellent } & \text { Very Good } & \text { Good } & \text { Fair } & \text { Poor } \\ 5 & 4 & 3 & 2 & 1\end{array}$

Data were analyzed using SPSS statistical software. Scores for the "ease of 
use" variable (item \#12 from the workshop evaluation questionnaire) were split into higher and lower scores, representing participants who experienced higher ease $(n=30)$ and lower ease $(n=30)$ of navigation in the virtual environment. Participants who rated ease of navigating within the virtual reality environment as "excellent" or "very good" were placed in the higher group, while those who rated the ease of navigation as "good", "fair', or "poor" were placed in the lower scores group.

c. Initial face to face simulation recording to assess the initial performance

d. Second face to face simulation recording to assess the last performance

A group of observers watched these recordings to evaluate individual team member performance. Evaluation performed on team skill dimensions (communication, collaboration, conflict management, team functioning and role playing), total team functioning, total team mean value also assigned to individuals. 


\section{Research Data Analysis}

Sixty graduates were recruited from several different programs of study at Algonquin College in Ottawa, Canada to work as participants on this study. They included recent graduates from Police Foundations, Nursing, Child and Youth Worker, and Paramedic programs. Graduates from these particular programs were chosen because they were likely to be exposed to domestic violence in their working environments, and a domestic violence scenario was to be the main simulation experience of the workshop. Participants were recent graduates of their respective programs who had not yet started working. They were each paid $\$ 300$ as consultants in the 2-day, 16 hour workshop. Approximately 300 recent graduates were approached, and were accepted on a first-come first-serve basis.

\subsection{Simulations Recording \& Performance Evaluation}

All simulations performed both in person and in the immersive virtual environment were recorded. These recordings were evaluated by six intructors to assess participants performance. The mean value of these assesments were used in the analysis.

Althought students were interviewed, the results of the interviews were only used to confirm the validity of the research. These data were not used in the research reported in this thesis. 


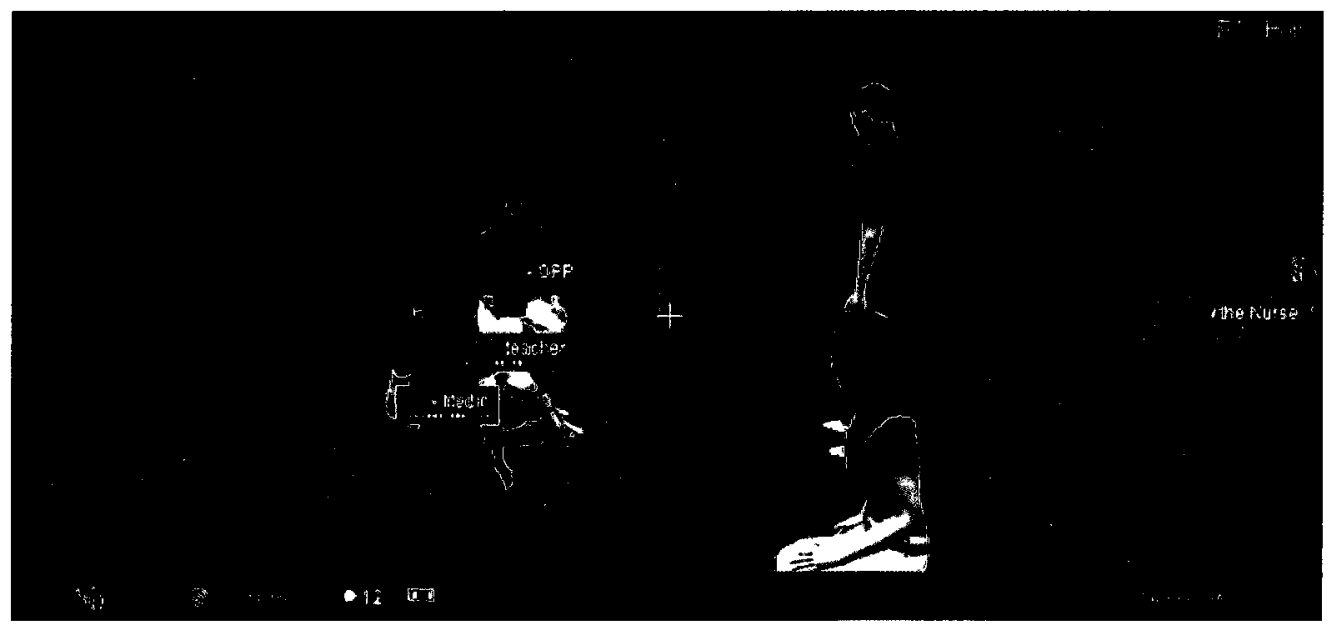

Figure 11. Student Indivudual Interview \& Student Group Interview

\subsection{Participants' Survey Results}

The participants' responses to the open-ended questions on the course evaluation were reviewed and major themes were identified. These themes are outlined below. Themes and responses are presented in greater detail in Appendix B.

\subsubsection{Comfort, Safety, and Teamwork}

Participant responses indicated comfort with using a virtual environment for simulation. Participants commented on being more comfortable and safer in virtual environment simulations than in real world simulations. They reported that it was an advantage to be able to participate in an emergency simulation while being in a comfortable and familiar physical environment. These feelings of comfort and safety allowed participants to be more engaged in the simulations in the virtual environment. For some the virtual environment shielded them from the anxiety of participation and simulations. For example, one participant wrote the following: "It was easy to get started, to be more involved, without being shy, especially with people I don't know and safe in 
virtual environment. Being in a game like environment with the protection of distance."

\subsubsection{Communication}

In general, participants made positive comments regarding the domestic violence simulation in the virtual environment. Some participants noted that the virtual environment forced a focus on verbal communication and as a result helped them to improve their communication skills. For example, one participant wrote the following: "... it takes people out of their comfort zone by removing the ability to touch a patient and rely totally on verbal communication skills."

Although the forced focus on verbal communication was helpful, participants also expressed having difficulty with the absence of the physical aspects of their roles, and with the absence of non-verbal information such as facial expressions of other participants during the simulation.

\subsubsection{The Virtual Environment}

In general, the experience of being in the virtual environment was reported to be fun and playful. Almost half of the participants $(n=27)$ commented on these aspects of the virtual environment. Participants appeared to accept the technology and many took the time to customize their avatars before immersing in the virtual environment. They reported enjoying the ability to customize their uniforms.

Although participants generally found it easy to navigate in the virtual environment, an introductory session was needed for both participants and course instructors to familiarize them with the basic aspects of controlling their avatars. Participants suggested that technical improvements could be made to the virtual 
environment through improving the repertoire of animations and the clarity of voice communications.

\subsubsection{Quantitative results}

For the survey item that asked participants to rate the virtual reality component of the workshop, the mean was $3.42(S D=.95)$ on a scale of 1 to 5 where 1 is poor and 5 is excellent. For the item that asked about the ease of navigating within the virtual environment, the mean was $3.70(S D=.99)$. These results indicate that the majority of participants rated the virtual environment and its ease of use as good or better. The breakdown of responses per response category is presented in Table 1.

\begin{tabular}{|l|l|l|l|l|l|}
\hline & Poor & Fair & Good & $\begin{array}{l}\text { Very } \\
\text { Good }\end{array}$ & Excellent \\
\hline $\begin{array}{l}\text { How would you rate the virtual reality } \\
\text { component of this course? }\end{array}$ & $3 \%$ & $4 \%$ & $23 \%$ & $23 \%$ & $6 \%$ \\
\hline $\begin{array}{l}\text { How would you rate the ease of navigating } \\
\text { within the virtual reality environment of this } \\
\text { course? }\end{array}$ & $1 \%$ & $3 \%$ & $24 \%$ & $16 \%$ & $16 \%$ \\
\hline
\end{tabular}

Table 1. Participant responses to virtual reality component of the workshop

\subsection{Telemetric}

Telemetric data was collected as a part of the pilot project using Web.Alive ${ }^{\text {TM's }}$ logging system and set of data analysis tools. Two types of data analysis that are possible using telemetric data are presented in Figure 6. In particular, we were able to observe the influence of time spent in conversation with other avatars on active duration within the 
virtual environment. The graphed findings suggest that the more users were actively participating in conversations within the virtual environment, the longer they stayed in the environment. This finding indicates the importance for instructors to find ways to encourage users to participate in conversations and interact with other avatars during learning sessions. We were also able to generate "heat maps" that indicate where avatars tended to congregate within the virtual environment.

The telemetric data collected provides the potential for further and more extensive quantitative analysis focused on learning in the virtual environment. Such quantitative analysis of features of learning in an immersive virtual environment may help to increase the overall effectiveness of education in both virtual and real-life classrooms in the future.

As a result, the research team collected a wealth of data to be analyzed from many different perspectives. This activity is ongoing Within the scope of this thesis, we wished to focus primarily on student performance evaluation and its results. 


\section{Results}

Data were analyzed using SPSS statistical software. Scores for the "ease of use" variable (item $\# 12$ from the workshop evaluation questionnaire) were split into higher and lower scores, representing participants who experienced higher ease $(n=30)$ and lower ease $(n=30)$ of navigation in the virtual environment. Participants who rated ease of navigating within the virtual reality environment as "excellent" or "very good" were placed in the higher group, while those who rated the ease of navigation as "good", "fair", or "poor" were placed in the lower scores group.

The independent $t$-test is used to test for a difference between two independent groups (like males and females) on the means of a continuous variable. Independent sample t-tests, were first used to compare the higher ease and lower ease groups in terms of their performance during the virtual-environment simulation. These two groups were compared with respect to observer ratings on eight variables from the TOSCE measure: communication; collaboration; roles and responsibilities; collaborative patient-family centered approach; conflict management/resolution; team functioning; overall individual performance; and overall team rating (see Table 2).

The dependent t-test (called the Paired-Samples T-Test in SPSS) compares the means between two related groups on the same continuous variable and identifies the significance level of the relationship between the groups and the continues variable. 


\begin{tabular}{|lr|l|l|l|}
\hline Ease of Use Divided into two & & N & Mean & Std. Dev. \\
\hline T1D1TM3CommTotal & Not Positive & 30 & 4.8333 & 1.16585 \\
& Positive & 30 & 5.2845 & 0.77553 \\
\hline T1D1TM3CollabMean & Not Positive & 30 & 4.8417 & 1.22031 \\
& Positive & 30 & 5.3621 & 0.96267 \\
\hline T1D1TM3RoleMean & Not Positive & 30 & 4.8167 & 1.22990 \\
& Positive & 30 & 5.5259 & 1.16563 \\
\hline T1D1TM3ConfManM. & Not Positive & 30 & 4.6833 & 1.07064 \\
& Positive & 30 & 5.3448 & 0.90241 \\
\hline T1D1TM3TeamMean & Not Positive & 30 & 4.7083 & 1.34882 \\
& Positive & 30 & 5.0317 & 1.15221 \\
\hline T1D1TM3TotalMean & Not Positive & 30 & 4.7583 & 1.20072 \\
& Positive & 30 & 5.3362 & 0.90207 \\
\hline T1D1TM3TeamRat.M & Not Positive & 30 & 4.9167 & 0.65104 \\
& Positive & 30 & 5.2155 & 0.60770 \\
\hline
\end{tabular}

Table 2. Virtual Simulation Independent T-Test Analysis

\begin{tabular}{|c|c|c|c|c|}
\hline & \multicolumn{4}{|c|}{ t-test for Equality Means } \\
\hline & $\mathrm{t}$ & $\mathrm{df}$ & $\begin{array}{l}\text { Sig. } \\
(2- \\
\text { tailed })\end{array}$ & $\begin{array}{l}\text { Mean } \\
\text { Diff. }\end{array}$ \\
\hline $\begin{array}{r}\text { T2CommMean } \\
\text { Equal Variances Assumed } \\
\text { Equal Variances Not Assumed }\end{array}$ & $\begin{array}{l}-1.744 \\
-1.755\end{array}$ & $\begin{array}{l}57 \\
50.637\end{array}$ & $\begin{array}{l}0.087 \\
0.085\end{array}$ & $\begin{array}{l}-0.45115 \\
-0.45115\end{array}$ \\
\hline $\begin{array}{r}\text { Equal Variances Assumed } \\
\text { Equal Variances Not Assumed }\end{array}$ & $\begin{array}{l}-1.815 \\
-1.822\end{array}$ & $\begin{array}{l}57 \\
54.825\end{array}$ & $\begin{array}{l}0.075 \\
0.074\end{array}$ & $\begin{array}{l}-0.52040 \\
-0.52040\end{array}$ \\
\hline $\begin{array}{rr}\text { T2RolesMean } & \begin{array}{r}\text { Equal Variances Assumed } \\
\text { Equal Variances Not Assumed }\end{array} \\
\end{array}$ & $\begin{array}{l}-2.272 \\
-2.274 \\
\end{array}$ & $\begin{array}{l}57 \\
\mathbf{5 6 . 9 7 9}\end{array}$ & $\begin{array}{l}0.027 \\
0.027\end{array}$ & $\begin{array}{r}-0.70920 \\
-0.70920\end{array}$ \\
\hline $\begin{array}{r}\text { T2ConflictMan.Mean } \\
\text { Equal Variances Assumed } \\
\text { Equal Variances Not Assumed }\end{array}$ & $\begin{array}{l}-2.562 \\
-2.569\end{array}$ & $\begin{array}{l}57 \\
55.976\end{array}$ & $\begin{array}{l}0.013 \\
0.013\end{array}$ & $\begin{array}{r}-0.66149 \\
-0.66149\end{array}$ \\
\hline $\begin{array}{l}\text { Equal Variances Assumed } \\
\text { Equal Variances Not Assumed }\end{array}$ & $\begin{array}{l}-1.814 \\
-1.819 \\
\end{array}$ & $\begin{array}{l}57 \\
56.162 \\
\end{array}$ & $\begin{array}{l}0.075 \\
0.074\end{array}$ & $\begin{array}{l}-0.59339 \\
-0.59339 \\
\end{array}$ \\
\hline $\begin{array}{rr}\text { T2TotalMean } & \text { Equal Variances Assumed } \\
\text { Equal Variances Not Assumed }\end{array}$ & $\begin{array}{l}-2.085 \\
-2.095 \\
\end{array}$ & $\begin{array}{l}57 \\
53.767\end{array}$ & $\begin{array}{l}0.042 \\
0.041\end{array}$ & $\begin{array}{r}-\mathbf{0 . 5 7 7 8 7} \\
\mathbf{- 0 . 5 7 7 8 7} \\
\end{array}$ \\
\hline $\begin{array}{r}\text { T2TeamRatingMeam } \\
\text { Equal Variances Assumed } \\
\text { Equal Variances Not Assumed }\end{array}$ & $\begin{array}{l}-1.821 \\
-1.823\end{array}$ & $\begin{array}{l}57 \\
56.933\end{array}$ & $\begin{array}{l}0.074 \\
0.073\end{array}$ & $\begin{array}{l}-0.29885 \\
-0.29885\end{array}$ \\
\hline
\end{tabular}

Table 3. Virtual World Simulation TOSCE Analysis 
Research results for the virtual reality simulation are represented below in the research model

\section{Virtual World Simulation Research Model}

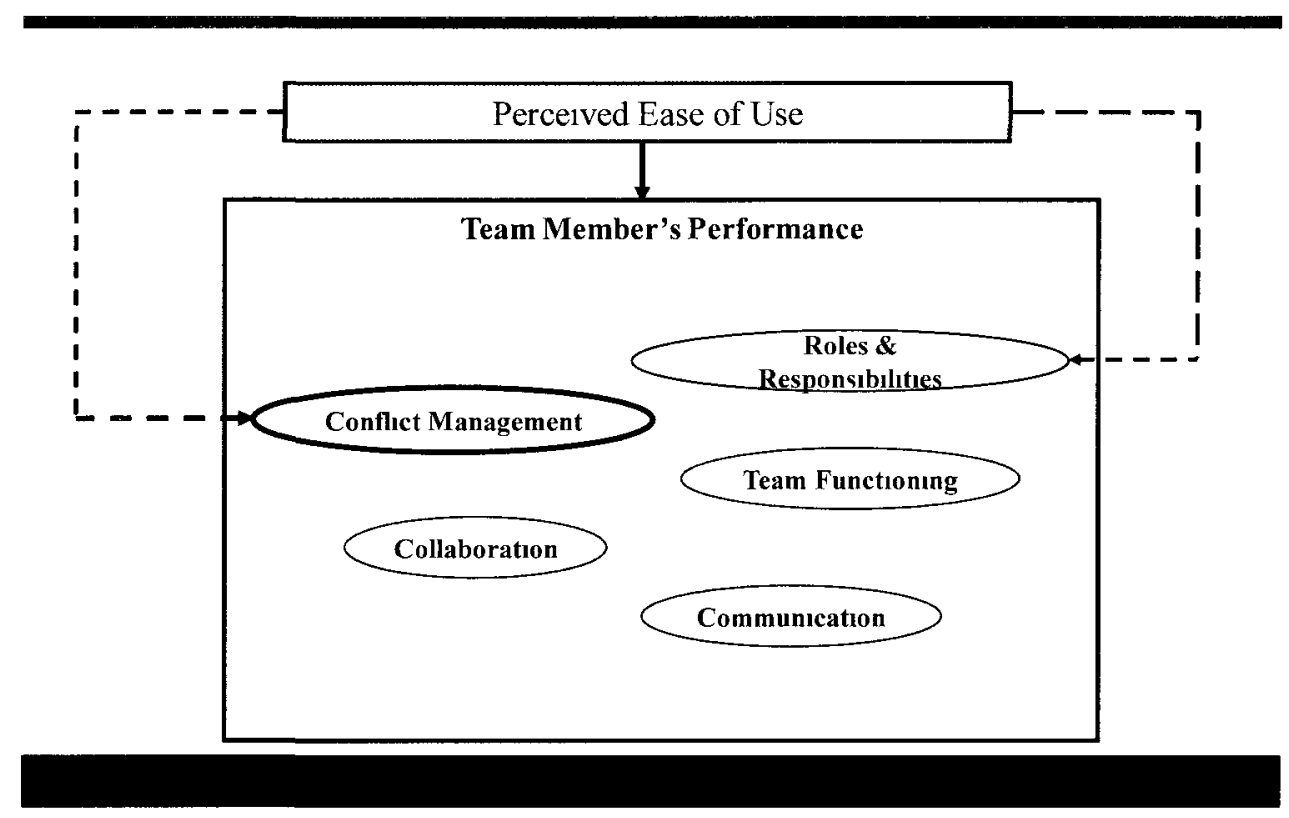

Figure 12. Vırtual Simulation Ease of Use and Team Work Performance

The second stage of the analysis involved comparing the higher and lower ease groups with respect to TOSCE scores from the first and final face-to-face simulations of the workshop These TOSCE ratıngs represent the level of interprofessional competence displayed by partıcıpants at the beginning and at the end of the workshop, respectively. Independent sample t-tests were used to compare the higher ease and lower ease groups on the eight TOSCE variables as rated during the first and final face-to-face simulation 
For the first face-to-face simulation, it should be noted that as expected no significant differences noticed in between higher ease and lower ease group while they are not using the technology. It is also important to note that no significant performance difference emerged either.

\begin{tabular}{|lr|l|l|l|}
\hline Ease of Use Divided into two & & $\mathbf{N}$ & Mean & Std. Dev. \\
\hline T1D1TM3CommTotal & Not Positive & 30 & 4.4333 & 0.78216 \\
& Positive & 30 & 4.7083 & 0.75167 \\
\hline T1D1TM3CollabMean & Not Positive & 30 & 4.4333 & 0.81720 \\
& Positive & 30 & 4.6083 & 0.58237 \\
\hline T1D1TM3RoleMean & Not Positive & 30 & 4.2917 & 0.82807 \\
& Positive & 30 & 4.4917 & 0.70858 \\
\hline T1D1TM3ConfManM. & Not Positive & 30 & 4.3750 & 0.73915 \\
& Positive & 30 & 4.5750 & 0.68276 \\
\hline T1D1TM3TeamMean & Not Positive & 30 & 4.3667 & 0.85029 \\
& Positive & 30 & 4.5417 & 0.72243 \\
\hline T1D1TM3TotalMean & Not Positive & 30 & 4.2583 & 1.01600 \\
& Positive & 30 & 4.5833 & 0.73793 \\
\hline T1D1TM3TeamRat.M & Not Positive & 30 & 4.4833 & 0.49971 \\
& Positive & 30 & 4.2750 & 0.38479 \\
\hline
\end{tabular}

Table 4. Initial Face-to-face Simulation Independent T-Test Analysis 
For the first face-to-face simulation, it should also be noted that, as expected, no statistically significant differences emerged between the higher ease and lower ease groups on any of the eight TOSCE variables (see Table 6). This indicates that there were no differences in interprofessional competence between higher ease and lower ease groups at the beginning of the workshop.

\begin{tabular}{|c|c|c|c|}
\hline & \multicolumn{3}{|c|}{$\begin{array}{l}\text { t-test for Equality of } \\
\text { Means }\end{array}$} \\
\hline & $\mathrm{t}$ & $\mathrm{df}$ & $\begin{array}{l}\text { Sig. } \\
(2- \\
\text { tailed })\end{array}$ \\
\hline $\begin{array}{r}\text { Equal Variances Assumed } \\
\text { Equal Variances Not Assumed }\end{array}$ & $\begin{array}{l}-1.388 \\
-1.388\end{array}$ & $\begin{array}{l}58 \\
57.909\end{array}$ & $\begin{array}{l}0.170 \\
0.170\end{array}$ \\
\hline $\begin{array}{r}\text { Equal Variances Assumed } \\
\text { Equal Variances Not Assumed }\end{array}$ & $\begin{array}{l}-0.955 \\
-0.955\end{array}$ & $\begin{array}{l}58 \\
52.416\end{array}$ & $\begin{array}{l}0.343 \\
0.344\end{array}$ \\
\hline $\begin{array}{r}\text { Equal Variances Assumed } \\
\text { Equal Variances Not Assumed }\end{array}$ & $\begin{array}{l}-1.005 \\
-1.005\end{array}$ & $\begin{array}{l}58 \\
56.646\end{array}$ & $\begin{array}{l}0.319 \\
0.319\end{array}$ \\
\hline $\begin{array}{r}\text { T1D1TM3ConflictManMean } \\
\begin{array}{r}\text { Equal Variances Assumed } \\
\text { Equal Variances Not Assumed }\end{array} \\
\end{array}$ & $\begin{array}{l}-1.089 \\
-1.089 \\
\end{array}$ & $\begin{array}{l}58 \\
57.639 \\
\end{array}$ & $\begin{array}{l}0.281 \\
0.281\end{array}$ \\
\hline $\begin{array}{r}\text { Equal Variances Assumed } \\
\text { Equal Variances Not Assumed }\end{array}$ & $\begin{array}{l}-0.859 \\
-0.859 \\
\end{array}$ & $\begin{array}{l}58 \\
56.525 \\
\end{array}$ & $\begin{array}{l}0.394 \\
0.394\end{array}$ \\
\hline $\begin{array}{r}\text { Equal Variances Assumed } \\
\text { Equal Variances Not Assumed }\end{array}$ & $\begin{array}{l}-1.418 \\
-1.418\end{array}$ & $\begin{array}{l}58 \\
52.936\end{array}$ & $\begin{array}{l}0.162 \\
0.162\end{array}$ \\
\hline $\begin{array}{r}\text { Equal Variances Assumed } \\
\text { Equal Variances Not Assumed } \\
\text { Equal }\end{array}$ & $\begin{array}{l}1.809 \\
1.809\end{array}$ & $\begin{array}{l}58 \\
54.444\end{array}$ & $\begin{array}{l}0.076 \\
0.076\end{array}$ \\
\hline
\end{tabular}

Table 5. Initial Face-to-Face Simulation TOSCE Analysis 


\section{Initial Face to Face Simulation Research Model}

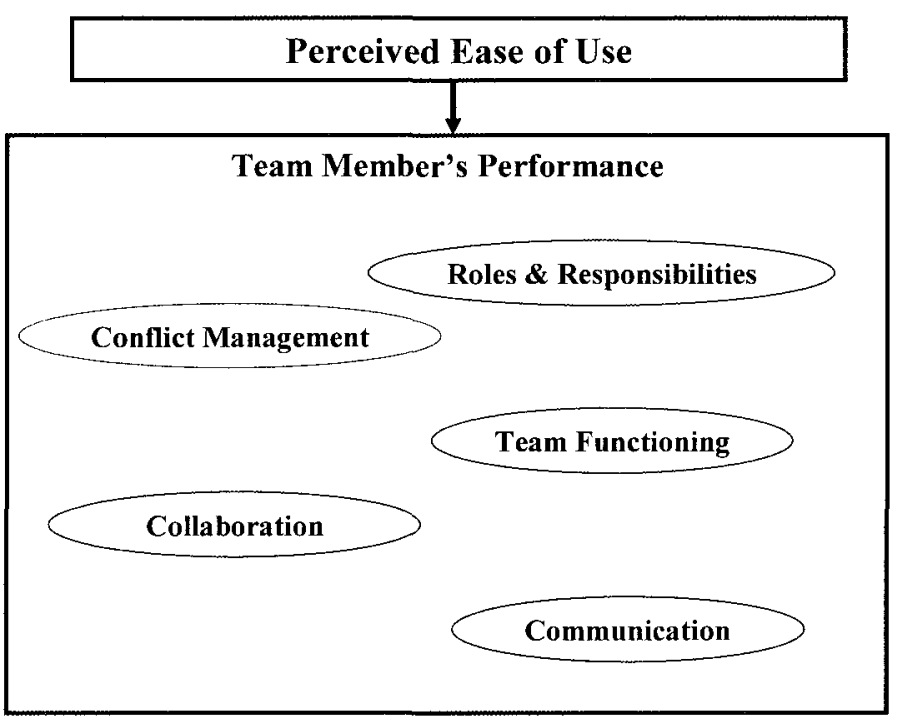

Figure 13. Face-to-face Simulation Ease of Use and Team Work Relationship:

No Relationship 
For the final face-to-face simulation, however, there were statistically significant differences between the higher ease and lower ease groups on all of the TOSCE dimensions (see Table $Z$ ). These results indicate that participants who found the virtual environment easier to navigate on average performed better at the final face-to-face simulation compared to those who found navigation in the virtual environment more difficult.

\begin{tabular}{|lr|l|l|l|}
\hline Ease of use divided into two levels & & $\mathrm{N}$ & Mean & $\begin{array}{l}\text { Std. } \\
\text { Deviation }\end{array}$ \\
\hline T3D1TM3CommMean & NotPositive & 30 & 5.3333 & 0.89137 \\
& Positive & 30 & 6.4167 & 2.33631 \\
\hline T3D1TM3CollabMean & Not Positive & 30 & 5.2917 & 0.76588 \\
& Positive & 30 & 5.9750 & 0.74380 \\
\hline T3D1TM3RoleMean & Not Positive & 30 & 5.4000 & 0.84486 \\
& Positive & 30 & 5.9250 & 0.76325 \\
\hline T3D1TM3ConflictManM & Not Positive & 30 & 5.1833 & 0.75980 \\
& Positive & 30 & 5.6250 & 0.73622 \\
\hline T3D1TM3TeamTotal & Not Positive & 30 & 5.3833 & 0.92320 \\
& Positive & 30 & 5.9917 & 0.79460 \\
\hline T3D1TM3TotalMean & Not Positive & 30 & 5.3417 & 0.91558 \\
& Positive & 30 & 5.8583 & 0.73015 \\
\hline T3D1TM3TeamRatingMean & Not Positive & 30 & 5.3583 & 0.74186 \\
& Positive & 30 & 5.7917 & 0.55353 \\
\hline
\end{tabular}

Table 6. Final Face-to-Face Simulation Independent T-Test Analysis 


\begin{tabular}{|c|c|c|c|c|}
\hline & \multicolumn{4}{|c|}{ t-test for Equality Means } \\
\hline & $\mathrm{t}$ & $\mathrm{df}$ & $\begin{array}{l}\text { Sig. (2- } \\
\text { tailed) }\end{array}$ & $\begin{array}{l}\text { Mean } \\
\text { Diff. }\end{array}$ \\
\hline $\begin{array}{l}\text { T3D1TM3CollabMean } \\
\text { Equal Variances Assumed } \\
\text { Equal Variances Not Assumed }\end{array}$ & $\begin{array}{l}-3.506 \\
-3.506 \\
\end{array}$ & $\begin{array}{l}\mathbf{5 8} \\
\mathbf{5 7 . 9 5 0} \\
\end{array}$ & $\begin{array}{l}0.001 \\
0.001\end{array}$ & $\begin{array}{l}-0.68333 \\
-0.68333 \\
\end{array}$ \\
\hline $\begin{array}{l}\text { T3D1TM3RoleMean } \\
\text { Equal Variances Assumed } \\
\text { Equal Variances Not Assumed }\end{array}$ & $\begin{array}{l}-2.526 \\
-2.526\end{array}$ & $\begin{array}{l}58 \\
57.411 \\
\end{array}$ & $\begin{array}{l}0.014 \\
0.014\end{array}$ & $\begin{array}{l}-0.52500 \\
-0.52500 \\
\end{array}$ \\
\hline $\begin{array}{l}\text { T3D1TM3ConflictManMean } \\
\text { Equal Variances Assumed } \\
\text { Equal Variances Not Assumed }\end{array}$ & $\begin{array}{l}-2.287 \\
-2.287\end{array}$ & $\begin{array}{l}\mathbf{5 8} \\
\mathbf{5 7 . 9 4 2}\end{array}$ & $\begin{array}{l}0.026 \\
0.026\end{array}$ & $\begin{array}{l}-0.44167 \\
-0.44167\end{array}$ \\
\hline $\begin{array}{r}\text { T3D1TM3TeamTotal } \\
\text { Equal Variances Assumed } \\
\text { Equal Variances Not Assumed }\end{array}$ & $\begin{array}{l}-2.735 \\
-2.735 \\
\end{array}$ & $\begin{array}{l}58 \\
56.742 \\
\end{array}$ & $\begin{array}{l}0.008 \\
0.008\end{array}$ & $\begin{array}{l}-0.60833 \\
-0.60833 \\
\end{array}$ \\
\hline $\begin{array}{r}\text { T3D1TM3TotalMean } \\
\text { Equal Variances Assumed } \\
\text { Equal Variances Not Assumed }\end{array}$ & $\begin{array}{l}-2.417 \\
-2.417 \\
\end{array}$ & \begin{tabular}{|l}
58 \\
55.263 \\
\end{tabular} & $\begin{array}{l}0.019 \\
0.019\end{array}$ & $\begin{array}{l}-0.51667 \\
-0.51667 \\
\end{array}$ \\
\hline $\begin{array}{r}\text { T3D1TM3TeamRatingMean } \\
\text { Equal Variances Assumed } \\
\text { Equal Variances Not Assumed }\end{array}$ & \begin{tabular}{|l|}
-2.564 \\
-2.564 \\
\end{tabular} & $\begin{array}{l}58 \\
53.650\end{array}$ & $\begin{array}{l}0.013 \\
0.013\end{array}$ & $\begin{array}{l}-0.43333 \\
-0.43333 \\
\end{array}$ \\
\hline
\end{tabular}

Table 7. Final Face-to-Face Simulation TOSCE Analysis 


\section{Second Face to Face Simulation Research Model}

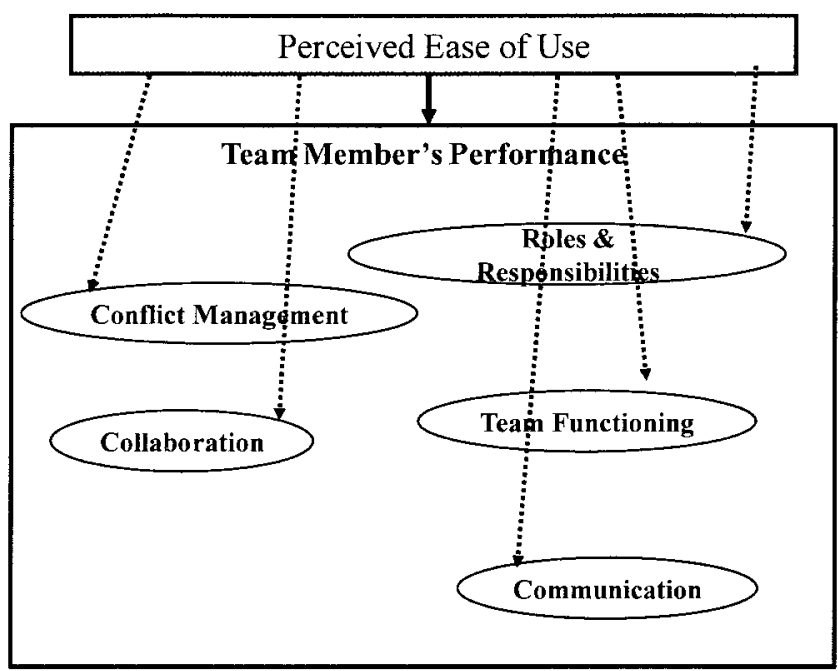

Figure 14. Third Simulation Ease of Use and Team Work Skills Relationship 


\section{Discussion}

\subsection{Research Findings}

Taken together, results from this study suggest that participants who reported higher ease of navigation in the virtual environment benefited more from the interprofessional education simulation than did those who reported lower ease of virtual environment navigation. The third face-to-face simulation shows strong relationship (Significant two tail $<0.05$ ) on all TOSCO values. There were no differences between higher ease and lower ease groups in terms of interprofessional competence during the first simulation (face-to-face) at the beginning of the workshop. Differences and strong relationship began to emerge, however, during the virtual environment simulation, and then even more differences emerged at the final face-to-face simulation.

The differences between those higher and lower in ease of navigation could represent a general level of technological familiarity that was present prior to the simulations, or they could represent the extent to which the orientation to the virtual environment was effective. Either way, baseline technological comfort level at the beginning of the workshop appears to impact participants' ability to gain from the virtual environment learning activities and to generalize them to later real world interactions. Those who were more comfortable in the virtual environment displayed higher levels of interprofessional competence by the end of the research simulations.

One very interesting observation is to highlight is the after effect of the ease of use in the simulation that no digital media is used, second face to face simulation. Data shows no major difference in terms of performance in the first simulation, which is face to face. 
Second simulation which is in virtual environment shows that lower Perceived Ease of Use negatively affects the overall performance, within TOSCE dimensions Conflict Management specifically. However, in the third simulation, even though no digital media is involved, the group having lower ease of use performed significantly worse than the group reporting high ease of use. That could be because in the second simulation (in Virtual Environment) lower ease group had to focus more on using the technology therefore benefited less from the simulation than the group at ease on using the technology. As overall, through attending these simulations participants improve their teamwork skills, as can be seen from the tables 2, 4, 6 independent t-test tables. These data suggest that the group with the lower ease of use did not benefit from the second simulation as much as the group with the high ease of use group.

These findings have implications for preparing learners for educational activities in an immersive virtual environment. If the level of technological comfort is related to learning outcomes, then a significant amount of time and attention should be paid to technological orientation at the beginning of virtual-environment workshops or courses to establish, to the extent possible, optimal levels of comfort with the technology.

Taking these results to the collaboration and team work level, research data suggest that, individuals at ease with the underlying technology would demonstrate team work skills more effectively. Difficulty with the use of the technology might first demonstrate an effect on conflict management skills. However, our research suggests that all other team work skills might be immediately affected as well and overall wider negative impacts on other significant team work skills may be observed. 
In order to confirm the effectiveness of immersive virtual spaces to practise team work skills, research team performed another study in Carleton Virtual, an immersive 3D virtual campus for Carleton University. Please refer to section 6.2 for detailed information on Carleton Virtual.

The students were divided into two groups. One group was introduced immediately to the 3D simulation; the other group interacted with a $2 \mathrm{D}$ simulation developed by the Friends of Bonnechere Parks. The 2D simulation was selected for comparison as it is a well-developed example of archaeological outreach and a teaching tool expressly meant to address the same issues as our own prototype.

Both groups of students were given graphing paper and recording sheets, and instructed to talk aloud as they sought to understand what the site they were looking at represented and they worked as a team. Afterwards, they were asked to complete a questionnaire, in order to enable cross-project comparability. These questions were assessed on a 5 point Likert scale, where the respondents indicated their degree of agreement with various statements:

Both kinds of simulation had their strengths and weaknesses (see Table 8), but the $3 \mathrm{D}$ simulation seemed to elicit stronger agreement from our use testers when asked if it helped develop understanding; it also seemed to be a better environment for fostering group/team learning. 
Table 8. Average Students Rating for 2D and 3D Archaeological Simulation

\begin{tabular}{|l|l|l|}
\hline $\begin{array}{l}\text { Questions were answered by rating from 0 (strongly disagree) to 4 } \\
\text { (strongly agree) }\end{array}$ & 3D & 2D \\
\hline 1. I feel that I have learnt something by using this system. & 3 & 1 \\
\hline 2. The excavation simulation reveals believable information. & 3.6 & 2.8 \\
\hline 3. I found it difficult to find out information about the archaeological site. & 1.4 & 2.6 \\
\hline 4. The quality of the material presented was consistent. & 3 & 1.8 \\
\hline $\begin{array}{l}\text { 5. I feel that using this system helps develop my understanding of fieldwork } \\
\text { methods and techniques. }\end{array}$ & 2.8 & 1.2 \\
\hline 6. I found the system educationally stimulating. & 3.4 & 0.8 \\
\hline 7. I was easily able to identify material culture. & 3 & 1.4 \\
\hline $\begin{array}{l}\text { 8. Tools provided allowed me to practice the theory relating to how } \\
\text { archaeology creates knowledge. }\end{array}$ & 2.4 & 1.8 \\
\hline 9. Working in a group helped me understand the excavation process. & 3.8 & 0.8 \\
\hline $\begin{array}{l}\text { 10. I found it useful to be able to identify where finds were located within } \\
\text { the site. }\end{array}$ & 2.8 & 1.8 \\
\hline 11. The descriptions of the artefacts I found were reasonable. & 3.2 & 1.4 \\
\hline $\begin{array}{l}\text { 12. I was able to find the tools and information I needed to maintain my } \\
\text { context sheets. }\end{array}$ & 1.6 & 1.8 \\
\hline 13. I would have preferred to work individually using the system. & 0.8 & 1.2 \\
\hline Average & $\mathbf{2 . 7}$ & $\mathbf{1 . 6}$ \\
\hline
\end{tabular}

Going back to our original hypotheses, our research data supports the hypotheses that there is a positive relationship between perceived ease of and performance $\mathrm{H} 1$.

H1: There is a positive relationship between Perceived Ease of Use and virtual team performance 
Following hypotheses are also supported with the data collected by this research.

H4: There is a positive relationship between Perceived Ease of Use and virtual team performance team functioning

H5: There is a positive relationship between Perceived Ease of Use and virtual team performance conflict management

Although following two hypotheses are supported on the third simulation, as an after simulation affect of Perceived Ease of Use, further study needs to be done before any conclusion be reached.

H2: There is a positive relationship between Perceived Ease of Use and virtual team performance collaboration component

H3: There is a positive relationship between Perceived Ease of Use and virtual team performance communication component

\subsection{Carleton Virtual}

This is a work-in progress environment and the data collected from this environment is still at preliminary stages. The study presented in this thesis more focuses on the Persephone project results. However, some of the highlights of Carleton Virtual are captured here as it is part of the overall research activity performed by the author.

Figure 15 shows the general structure of Carleton Virtual built using web.alive technology. As shown in this figure, CV provides spaces for lectures, various presentations, collaboration, social interaction and special activities.

This will allow instructors and other participants to easily access content and update it in real time while in the environment. The system allows 3D spatial audio. The sound level can be independent of distance (e.g. for speakers in the lecture hall) or 
change based on avatars distance (for local talks). At any time, users can know who can hear them, and also can control different audio features such as temporary mute. Different "areas" can be defined to simplify environmental control (e.g. private meetings) and behavioural monitoring (e.g. who goes where, etc).

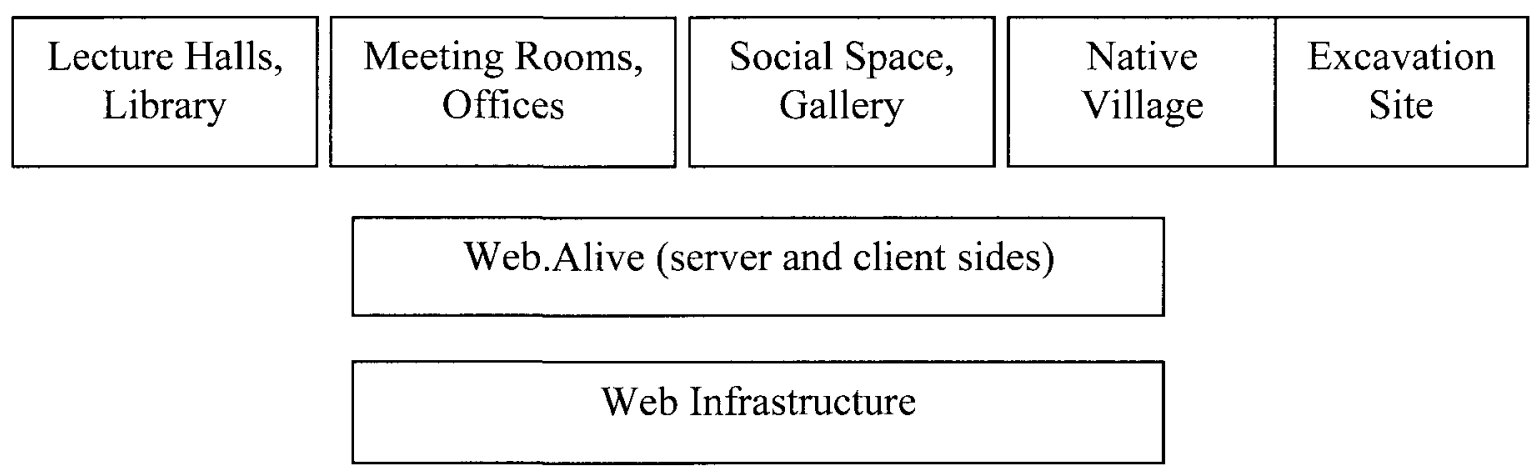

Figure 15. General Structure of the Carleton Virtual

As shown in Figure 16, the environment was designed to resemble the actual Carleton University campus. The design keeps some of the characteristic features and elements of the campus but allows modifications to improve the space usage and customize it for the virtual activities. The content presentation is done through surfaces (screens) that can show videos, images, presentation files (supporting Powerpoint and PDF), and real-time web pages. . This will allow instructors and other participants to easily access content and update it in real time while in the environment. The system allows 3D spatial audio. 


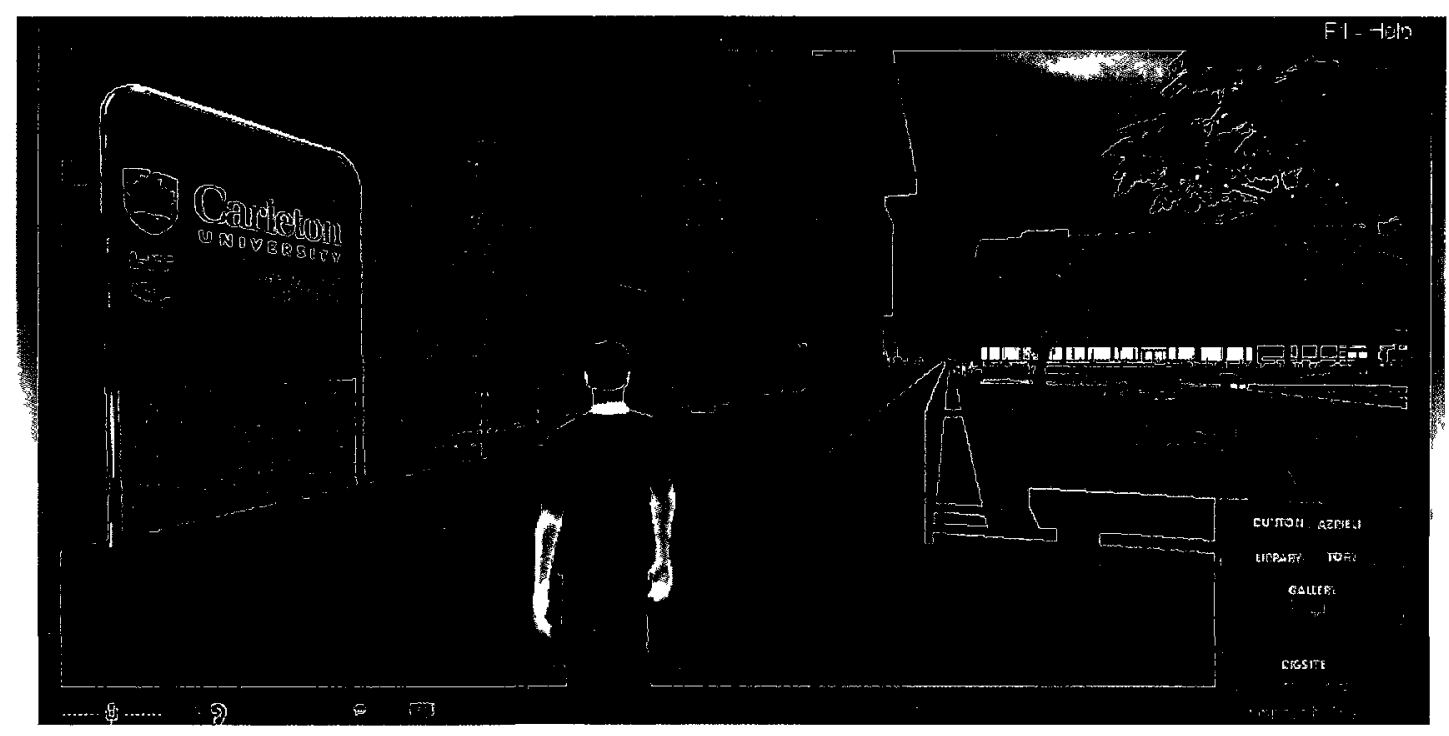

Figure 16. A View from Quad Area

Carleton Virtual is designed to support two case studies initially:

Language Case: The current trend towards "hybrid" or "blended" learning in post-secondary education is driven by the ever increasing access to various modes of technology, student familiarity with these technologies and changes in learner attitudes towards learning. Today's tech savvy students demand more choices as a result of different learning styles, work and study schedules, and access to relevant physical learning spaces. As educators we need to keep up with the changing needs of our students by planning and facilitating creative learning opportunities in relevant and stimulating environments. 3D virtual environments, such as Carleton Virtual, provide just that space.

This particular project was designed so that students in an Academic ESL class could benefit from unique opportunities to practice speaking and collaborating with their classmates using a common linguistic reference (English) in a risk-free environment. The 3D Carleton Virtual (CV) environment allowed students to collaborate, at their 
convenience, in a space that replicated the Carleton campus library, but that was mutually convenient to the participants in terms of time and accessibility.

This immersive learning opportunity made use of the existing Carleton Virtual framework. In particular, students were encouraged to meet in any of the ten designated library rooms and final presentations were held in an auditorium. Once completed, the 3D Gallery (a new building addition to CV campus) will be an excellent space for students to host poster project presentations and seminars.

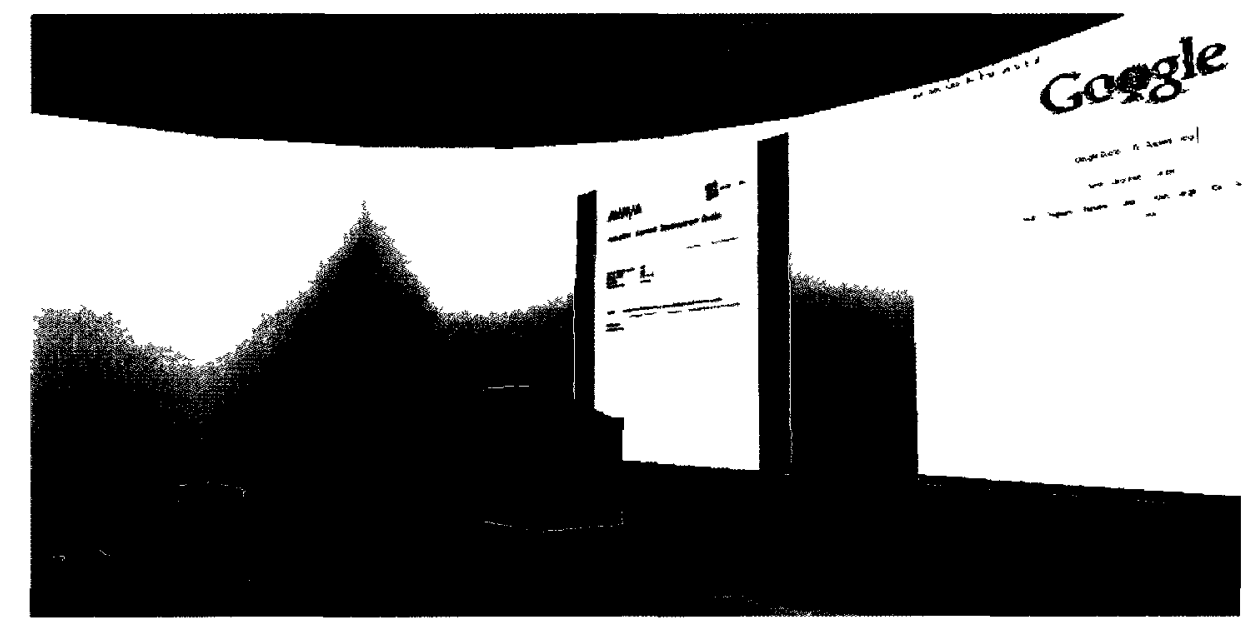

Figure 17. Presentation Area

Archeological Case: The truth-value of archaeology is not self-evident. There is a huge gulf between the primary data and the "final" interpretation. The training of archaeologists typically takes place in North American within the confines of academic archaeology. In that context, students' experience of archaeology tends to be short summer field experiences. We are loath to allow students to really get their hands on real archaeology because it is a limited resource and there isn't the time, money, or resource to allow our students to make mistakes. There is of course more to archaeology than simply field work, but even in those cases, there is a reluctance to allow students to 
actually work with the materials, to make mistakes. In some institutions, it is entirely possible to graduate with a degree in archaeology without ever having spent more than two weeks doing field work (Graham's experience).

There has been a shift in educational practice taking place over the last decade or so, from what might be called "teacher-centric" to "learner-centric" approaches. The latter recognizes that students learn in different styles. It does not aim to transfer knowledge from the teacher to the student, but to give the student the appropriate tools to create knowledge themselves. Virtual worlds are an excellent location for allowing knowledge creation to emerge. Our virtual prototype excavation, which we have usetested with a small cadre of students, demonstrates that even something as complex as archaeological knowledge is amenable to this kind of education.

The prototype immersive archaeological experience is built on the results of a 2003 excavation conducted by Shawn Graham (Carleton University) and Andrea Bradley (Institute for Field Archaeologists, UK) in Shawville Quebec (Bibliographie de l'inventaire des sites archéologiques du Québec MCCQ 3453, rapport inédit). That excavation was conducted in the context of a community revitalization project, and was designed to introduce high school students to their community's heritage as a summer field school in archaeology. The site was the Armstrong Brickyards, an industrial heritage site. A heritage park was proposed for the site, the 'Armstrong Heritage Farm' which covers an area of ca. 37 acres in Lot 6 , Range 6 of Clarendon Township. The village of Shawville is notable in Quebec for its ethnic make-up of primarily Irish Protestants. Shawville sits on clay beds left over from the Champlain Sea; these clay beds were the source for a thriving brick industry in the late 19 th century. One brickyard belonging to G. 
F. Hodgins was situated south of the village; another, belonging to the Armstrong family was situated to the east on Lot 6 . All surface traces of this brickyard have long since been erased. The excavation was directed with the intention of discovering the functional layout and extent of this brickyard on the property slated for development. We took the results of that excavation, and simulated one of the $2 \mathrm{~m} \times 2 \mathrm{~m}$ trenches in the web.alive environment, creating soil layers, features, and artefacts in their relative correct positioning.

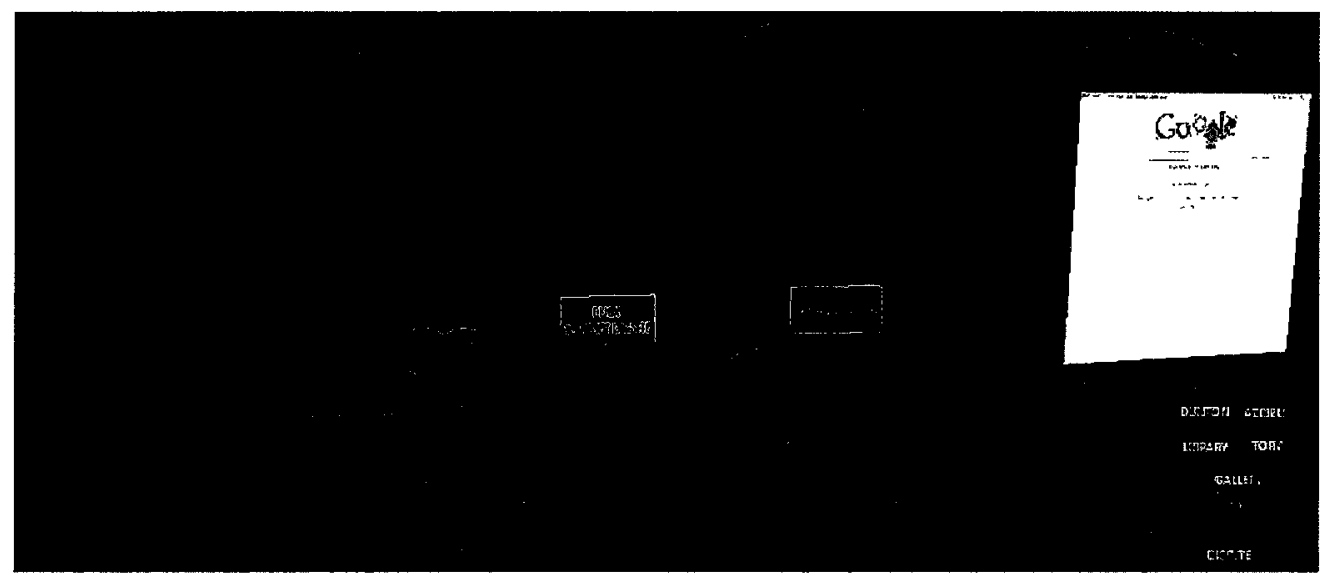

Figure 18. Carleton Virtual Archeological Excavation Site 


\section{Conclusion}

Virtual teams are becoming an important structural element of any successful organizations. It is important for business leaders to make sure that virtual teams are affective and highly productive. Highly competitive nature of the current economical conditions does not give the luxury to companies to keep under-performing teams on board. Therefore, studies highlighting the reasons for virtual teams to under-perform provide valuable insight to business leaders and suggest actions might be taken to help teams to increase their performance.

Author of these pages believes that this study provides a valuable contribution to virtual team research stream by highlighting the significant positive relationship between ease of use and performance, along with supporting data. The strong tie between Perceived Ease of Use and Conflict Management Skill needs close attention as well as long term negative impact of Perceived Ease of Use on all team work skill dimension that were studied.

There are three major contributions from this research:

- This research contributes to virtual team and performance stream of research by providing data supporting this view and taking the existing research a step further by studying the impact on the team work performance dimensions. As stated clearly in organizations must consciously create conditions to for effective teamwork (Berry, 2011). Conflict management and effective team role playing are some of the major issues reported by researchers (Magnus et 
al, 2011). Our research suggests that using a technology all members feeling at ease will effect team performance positively.

- Our second contribution is to the technology and user acceptance research stream. This research contributes to this stream of research by providing data supporting the assumption that there is a positive relationship between intention of usage of the technology and user's performance. As stated in some of the papers, there was little research in the literature supporting this hypothesis. 'An important aspect of future research is to tie this model into other work streams, examining the association between user acceptance and organizational and individual usage outcomes. (Venkatesh et al., 2003). This research contributes to this stream of research by providing data supporting the assumption that there is a positive relationship between intention of usage of the technology and user's performance.

- The case studies presented in this study demonstrate how a 3D Virtual Environment can be used as a learning tool by providing a virtual space that (1) allows people in different locations to interact, (2) gives users access to facilities not available physically, (3) enables activities that are not possible in physical settings, and (4) offers a variety of observation and measurement tools for performance evaluation and improvement. Callaghan et al. (2009) also report the use of Second Life for technology education. They notice the need for some simplifications (for example in teaching engineering equipments) which can be a problem but also mention partial integration with a content management system (Moodle) which is a considerable advantage. 
Danilicheva et al. explore the educational values of 3D virtual worlds but from a storytelling point of view.

Result of this study points couple of future direction for the fellow researchers. It was a limitation of the current study to be able to observe teams for only a short duration. Extended period of observation would give more data and might highlight more complex relationship between ease of use and each team work dimensions.

It would be also interesting to study the relationship between Perceived Ease of Usefulness and performance relationship. This study only focused on Perceived ease of Use and Performance relationship.

Telemetric is another area for the future researchers to focus on. Due to a resource and time limitation of the current study, huge amount of telemetric data collected during this study could not be investigated. It is the intention of the author of this study to apply social network analysis to telemetric collected to find our social network metrics for each team member. It would be extremely interesting to study the relationship between social network metrics of team members with individual' and team performance.

Following publications presented / submitted to internationals conferences and journals as a result of the study reported in this thesis:

- Nuket Nowlan, Eleanor Riesen, Michelle Morley, Ali Arya, and Nicholas Sauriol, "A Framework for an Immersive Learning Environment with Telemetrics and Simulation," published in Ubiquitous Learning: An International Journal, 2010 
- Ali Arya, Peggy Hartwick, Shawn Graham, Nuket Nowlan, "Virtual Environment as a Learning Space: Two Case Studies, " presented in IETC-2011, Istanbul, Turkey. 2011 http://www.iet-c.net/

- Ali Arya, Nuket Nowlan, Nicholas Sauriol, "Data-driven Framework for an Online 3D Immersive Environment for Educational Applications," presented in EduLearn-10 - Barcelona, Spain, July 5-7, 2010.

- Nuket Savaskan Nowlan, Ali Arya, Eleanor Riesen, Michelle Morley, "The Effect of Perceived Ease of Use on Virtual Team Performance", to be presented in Ubiquitous Learning 2011, Berkeley, US, November 2011. http://q11.cgpublisher.com/proposals/75

- Ali Arya, Peggy Hartwick, Shawn Graham, Nuket Nowlan, "Case Studies on the Use of Virtual Spaces for Education", Submitted to Journal of Interactive Media in Education, 2011 


\section{Appendix A}

\section{Advanced Communication and Problem-solving in Teams course Evaluation Form}

The face to face component included:

- In person learning sessions

- Simulation scenarios

- $\quad$ Class discussions

The online component included:

- $\quad$ Online learning modules

- Online discussion boards

- Blackboard

The virtual reality component included:

- Working with an avatar

- Virtual simulation scenarios

- Virtual discussions in virtual reality environment

Instructions: Please complete the form and return it to the course facilitator

1. Overall did you find this course helpful in preparing you for your work? Y/N Please describe.

2. How would you rate the face to face component of this course?

$\begin{array}{lllll}\text { Excellent } & \text { Very Good } & \text { Good } & \text { Fair } & \text { Poor } \\ 5 & 4 & 3 & 2 & 1\end{array}$

3. Please describe what you liked about the face to face component of this course.

4. Please describe what could be improved on the face to face component of this course.

5. How would you rate the online component of this course?

$\begin{array}{lllll}\text { Excellent } & \text { Very Good } & \text { Good } & \text { Fair } & \text { Poor } \\ 5 & 4 & 3 & 2 & 1\end{array}$

6. Please describe what you liked about the online component of this course. 
7. Please describe what could be improved in the online component of this course.

8. How would you rate the virtual reality component of this course?

$\begin{array}{lllll}\text { Excellent } & \text { Very Good } & \text { Good } & \text { Fair } & \text { Poor } \\ 5 & 4 & 3 & 2 & 1\end{array}$

9. Please describe what you liked about the virtual reality component of this course.

10. Please describe what could be improved in the virtual reality component of this course.

11. Was the timeframe appropriate for completing the objective of this course?

- Yes

- $\quad$ No

Comments:

12. How would you rate the ease of navigating within the virtual reality environment of this course?

$\begin{array}{lllll}\text { Excellent } & \text { Very Good } & \text { Good } & \text { Fair } & \text { Poor } \\ 5 & 4 & 3 & 2 & 1\end{array}$

13. Please describe what you liked about navigating within the virtual reality environment of this course.

14. Please describe what could be improved to ease navigation within the virtual reality environment of this course.

15. Overall, what is the most meaningful thing you will take away from this learning experience?

16. Additional Comments

Please tell us a bit about yourself....

Which program are you enrolled in?

OChild and Youth Worker

ONursing

OParamedic Services

OPolice Services

Your gender: 

O Female
O Male

Your age range:
O Under 18
O $18-20$
○ 21-25
O $26-30$
O 31 and older

I have had previous experience working in interprofessional teams.
O Yes
- No
Unsure

Thank you for your time and suggestions 


\section{Appendix B}

\section{Scoring Instructions}

1. Insert one team members' name at the top of each column.

2. Observe the participants during the team meeting discussion. Please do not interrupt them.

3. Using the 9-point scale, assess each team member's ability to demonstrate the 6 core objectives listed on the Assessment Sheet. Insert a score for each objective observed for each team member. The expectation for the team is to demonstrate all or most of the competencies outlined in the descriptions.

4. Some objectives may not be applicable or observed. If you feel that a particular objective is not applicable to that team member mark that box as NA.

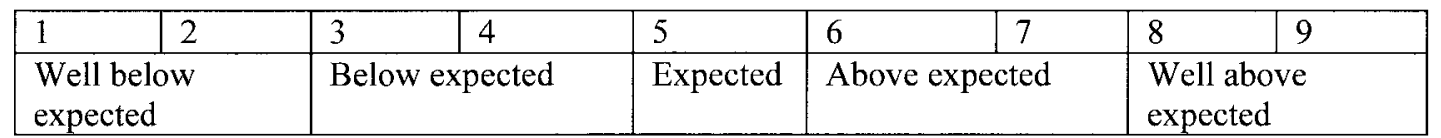

\begin{tabular}{|c|c|c|c|c|}
\hline \multirow[b]{2}{*}{ DEMONSTRATES THE FOLLOWING: } & \multicolumn{4}{|c|}{ Participants } \\
\hline & Nurse & CYW & Paramedic & Police \\
\hline $\begin{array}{l}\text { Communication } \\
\text { Communicates and expresses ideas in an } \\
\text { assertive and respectful manner; uses } \\
\text { communication strategies in an effective } \\
\text { manner with others. }\end{array}$ & & & & \\
\hline $\begin{array}{l}\text { Collaboration } \\
\text { Establishes collaborative relationships with } \\
\text { others; promotes the integration of } \\
\text { information and perspectives from others; } \\
\text { ensures that appropriate information is shared } \\
\text { with other providers. }\end{array}$ & & & & \\
\hline $\begin{array}{l}\text { Roles and Responsibilities } \\
\text { Describes one's own roles and responsibilities } \\
\text { in a clear manner; describes the roles and } \\
\text { responsibilities of other providers; shares best } \\
\text { practice knowledge with others; accepts } \\
\text { accountability for one's contributions. }\end{array}$ & & & & \\
\hline $\begin{array}{l}\text { Collaborative Patient-Family Centred } \\
\text { Approach } \\
\text { Seeks input from patient and family in a } \\
\text { respectful manner re: feelings, beliefs, needs } \\
\text { and care goals; integrates goals, values, and } \\
\text { circumstances into care plans; shares options } \\
\text { and health care information with patients and } \\
\text { families; advocates for patient and family as } \\
\text { partners in decision-making processes. }\end{array}$ & & & & \\
\hline $\begin{array}{l}\text { Conflict Management/Resolution } \\
\text { Demonstrates active listening and is respectful } \\
\text { of different perspectives and opinions from }\end{array}$ & & & & \\
\hline
\end{tabular}




\begin{tabular}{|c|c|c|c|c|}
\hline & \multicolumn{4}{|c|}{ Participants } \\
\hline DEMONSTRATES THE FOLLOWING: & Nurse & CYW & Paramedic & Police \\
\hline $\begin{array}{l}\text { others; works with others to prevent and deal } \\
\text { effectively with conflict. }\end{array}$ & & & & \\
\hline $\begin{array}{l}\text { Team Functioning } \\
\text { Evaluates team function and dynamics; } \\
\text { demonstrates shared leadership within the } \\
\text { healthcare team that is appropriate to the } \\
\text { situation; contributes effectively and } \\
\text { meaningfully in interprofessional team } \\
\text { discussions. }\end{array}$ & & & & \\
\hline
\end{tabular}

\section{Instructions for Global Rating Scores}

Observer

- Please do not use individual IPE competency scores from the previous page to determine the Global Score for either the Team or the Individual participant

- Using the scale below, please assign a global rating score for both the Team as a whole and the individual participants.

- This score should reflect your overall assessment of a) how well the team worked together to address the issue presented to them and b) the individual participant's contribution to the team

- RED FLAG(S): Please check the box ( $\square$ ) if an individual's decision/advice (care plan) put the patient at risk.

*Reminder: The expectation for the team is to demonstrate all or most of the competencies outlined in the descriptions 


\begin{tabular}{|l|l|l|l|l|l|l|l|l|l|}
\hline Global Scores & $\begin{array}{l}\text { Well } \\
\text { below } \\
\text { expected }\end{array}$ & \multicolumn{2}{l|}{$\begin{array}{l}\text { Below } \\
\text { expected }\end{array}$} & \multicolumn{2}{|l|}{ Expected } & \multicolumn{2}{|l|}{$\begin{array}{l}\text { Above } \\
\text { expected }\end{array}$} & \multicolumn{2}{l}{$\begin{array}{l}\text { Well } \\
\text { above } \\
\text { expected }\end{array}$} \\
\hline & $\mathbf{1}$ & $\mathbf{2}$ & $\mathbf{3}$ & $\mathbf{4}$ & $\mathbf{5}$ & $\mathbf{6}$ & $\mathbf{7}$ & $\mathbf{8}$ & $\mathbf{9}$ \\
\hline $\begin{array}{l}\text { Individual Rating } \\
\text { for }\end{array}$ & & & & & & & & & \\
\hline $\begin{array}{l}\text { Individual Rating } \\
\text { for }\end{array}$ & & & & & & & & & \\
\hline $\begin{array}{l}\text { Individual Rating } \\
\text { for }\end{array}$ & & & & & & & & & \\
\hline $\begin{array}{l}\text { Individual Rating } \\
\text { for }\end{array}$ & & & & & & & & & \\
\hline $\begin{array}{l}\text { Individual Rating } \\
\text { for }\end{array}$ & & & & & & & & & \\
\hline $\begin{array}{l}\text { Individual Rating } \\
\text { for }\end{array}$ & & & & & & & & & \\
\hline \hline Team Rating & & & & & & & & & \\
\hline
\end{tabular}


For Red Flags please describe the patient safety issue:

Additional Comments: 


\section{Appendix C}

Summary of Comments from IPE Pilot-Virtual World Responses

\begin{tabular}{|c|c|}
\hline Themes & Responses \\
\hline Safety & $\begin{array}{l}\text { Like a game to try different things without being judged } \\
\text { Like a mask so I will feel safe to be there } \\
\text { Have increased comfort level in discussions } \\
\text { "It was easy to get started, be more involved, without being } \\
\text { shy, especially with people I don't know." }\end{array}$ \\
\hline \multicolumn{2}{|l|}{ Time to Think } \\
\hline $\begin{array}{l}\text { Practice } \\
\text { Communication }\end{array}$ & $\begin{array}{l}\text { Need more communication options and personal interaction } \\
\text { Able to practice communication skills without being rushed } \\
\text { Communicating verbally was the only way to accomplish } \\
\text { goals (6) } \\
\text { Like the opportunity to have verbal discussions as opposed to } \\
\text { verbal chat } \\
\text { "...it takes people out of their comfort zone by removing the } \\
\text { ability to touch a patient and rely totally on verbal } \\
\text { communication skills." } \\
\text { Focus on verbal communication (6) } \\
\text { "Hard to build therapeutic relationship with the patient." } \\
\text { Peer discussions }\end{array}$ \\
\hline $\begin{array}{l}\text { Delivery Mode, } \\
\text { Teaching Mode }\end{array}$ & $\begin{array}{l}\text { Fun, change of pace (5), something different (5), engaging } \\
\text { (2), interesting new approach (5), innovative (3), interactive } \\
\text { (2) } \\
\text { Can do from home (3) } \\
\text { Need to see people's faces } \\
\text { Need more time to practice with avatar } \\
\text { Good instructions for using VR } \\
\text { Interactive (2) } \\
\text { Ease of creating scenarios without being there } \\
\text { Like videos } \\
\text { Liked simulations in VR (2), "a lot of potential for practicing } \\
\text { scene management in emergency care" } \\
\text { Hard to simulate everything in real life } \\
\text { Like to make own character } \\
\text { Need to have goals when being oriented to the environment- } \\
\text { get bored } \\
\text { Able to accomplish something by following the instructions } \\
\text { in order to navigate the virtual world } \\
\text { Need technical support for problems (ex. Stuck in water) } \\
\text { Need longer orientation/tutorial (2) } \\
\text { Face to face is most important. VR is a supplement to F to F }\end{array}$ \\
\hline
\end{tabular}




\begin{tabular}{|c|c|}
\hline & $\begin{array}{l}\text { Important to meet participants in VR, } \mathrm{f} \text { to f first to establish a } \\
\text { relationship } \\
\text { Can be in different locations and still communicate } \\
\text { Like avatars } \\
\text { New technology is always interesting } \\
\text { All equipment should be provided to students so there are no } \\
\text { extra expenses } \\
\text { Looks real, you can talk and move and text } \\
\text { "It seems like this should have been a component in school a } \\
\text { long time ago" }\end{array}$ \\
\hline $\begin{array}{l}\text { Technical } \\
\text { Modifications }\end{array}$ & $\begin{array}{l}\text { Need joystick option (2) } \\
\text { Need to ease navigation, programmable keys for those who } \\
\text { are not right handed, need left handed option ( } 3 \text { ) } \\
\text { Need arrow key option (3) } \\
\text { Need mouse click to enter buildings } \\
\text { Easy to move around (6) } \\
\text { Need to work on controls (ex. Move out of kneeling position, } \\
\text { each profession to have its own actions) (3) } \\
\text { More actions/functions for avatars (6) (like sims 2-pc game, } \\
\text { need vital signs, physical aspects) } \\
\text { Larger more detailed world } \\
\text { Sluggish controls at times ( } 4 \text { ) } \\
\text { Wider doors } \\
\text { Improve technical aspects (12) } \\
\text { Make the mouse visible so you know where the pointer is } \\
\text { Lag time between person talking ( } 2 \text { ) } \\
\text { Need to be easier to access videos } \\
\text { Hard to hear at times } \\
\text { Need to be installed on the computer before it is used (2) } \\
\text { Better camera rotation } \\
\text { Buggy, difficult to do in a public setting } \\
\text { Better map of the world ( } 3 \text { ) } \\
\text { Shorter load times } \\
\text { Customizing the avatar is good ( } 2 \text { ) } \\
\text { Like being able to walk, run, and jump } \\
\text { Have instructions on the top of the screen } \\
\text { Instructions were clear and explicit } \\
\text { Private chats (speaking) } \\
\text { Teachers need more "power" in VR and to speak to everyone } \\
\text { without a mic and be able to take away speaking from other } \\
\text { students or give student "power"to speak } \\
\text { It was in a circle, hard to get lost } \\
\text { Audio, fixing speech volumes } \\
\text { Like the feel of another world }\end{array}$ \\
\hline
\end{tabular}




\begin{tabular}{|l|l|l|}
\hline & Interaction in real time setting & \\
\hline Teamwork & $\begin{array}{l}\text { "...allowed me to relax, and be part of a team while observing } \\
\text { other team members." } \\
\text { I like having more team collaboration }\end{array}$ & \\
\hline & & \\
\hline & & \\
\hline
\end{tabular}




\section{REFERENCES}

Aram, J. D., \& Morgan, C. P. (1976). The role of project team collaboration in R\&D performance. Management Science, 22(10), 1127-1137.

Berry Gregory R. (2011). Enhancing Effectiveness on Virtual Teams. Journal of Business Communication, Volume 48, Number 2, 186-206.

$\begin{array}{llllll}\text { Bullack, } & \text { C } & \text { Klein, } & \text { J } & \text { (2010). }\end{array}$ http://www.brandman.edu/pdf/virtual_teams_brandman_forrester_white_paper.pdf

Cascio, W. F. (2000). Managing a virtual workplace. Academy of Management Executive, 14, 81-90.

Callaghan, M.J., et al. (2009). Teaching Engineering Education using Virtual Worlds and Virtual Learning Environments. International Conference on Advances in Computing, Control, and Telecommunication Technologies

Chidambaram, L. (1996). A study of relational development in computer supported groups. MIS Quarterly, 29(2), 143-165.

Comstock, D. \& Fox, S. (1995). Computer conferencing in a learning community: opportunities and obstacles. 1995. http:/www.seattleantioch.edu/VirtualAntioch/DRAFT7HT.HTM (14/04/1998).

Cramton, C. D. (2001). The mutual knowledge problem and its consequences for dispersed collaboration. Organization Science, 12, 346-371.

Danilicheva, P., et al, (2009). Education in Virtual Worlds: Virtual Storytelling, International Conference on CyberWorlds

Davis, F. D. (1989). Perceived usefulness, perceived ease of use, and user acceptance of information technology. MIS Quarterly, 13(3), 319-339.

de Lisser, E. (1999). Update on small business: Firms with virtual environments appeal to workers. Wall Street Journal, B2.

Fetscherin, M. \& Lattemann, C. (2008). User acceptance of virtual worlds. Journal of Electronic Commerce Research, 9(3), 231-242.

Galileo Educational Network (2008). Guide to assessing Teamwork and collaboration. http://www.galileo.org/tips/rubrics/t-c_rubric.pdf

Gibson, C. B. \& Cohen, S. G. (2003). Virtual teams that work: Creating conditions for virtual team effectiveness. San Francisco, Jossey-Bass. 
Handy, C. (1995a). Managing the dream. in Chawla and Renesch (Eds), Learning Organizations: Developing Cultures for Tomorrow's Workplace, Productivity Press, Portland, OR.

Handy, C. (1995b). Trust and the virtual organization. Harvard Business Review, MayJune, pp. 2-8.

Hiltz, S. R., Johnson, K., \& Turoff, M. (1986). Experiments in group decision-making: Communication process and outcome in face-to-face versus computerized conferences. Human Communication Research, 13(2), 225-252.

Holton, J.A. (2001). Building trust and collaboration in a virtual team. Team Performance Management, 7(3/4), 36-47.

Hu, P., Chau, P., Liu Sheng, O. R., \& Tam, K. (1999). Examining the technology acceptance

model using physician acceptance of telemedicine technology. Journal of Management Information Systems, 16, 91-112.

Jehn, K.A. \& Mannix, E.A. (2001). The dynamic nature of conflict: Longitudinal study of intragroup conflict and group performance. Academy of Management Journal, 44, 238251.

Johnson, P., Heimann, V., \& O'Neill, K. (2001). The "wonderland" of virtual teams. Journal of Workplace Learning, 13(1), 24-30.

Kanawattanachai, P. \& Yoo, Y. (2002). Dynamic nature of trust in virtual teams. Journal of Strategic Information Systems, 11(3-4), 187-213.

Kayworth, T. \& Leidner, D.E. (2000). The global virtual manager: A prescription for success. European Management Journal, 18(2), 183-192.

Kharif, O. (2007). The virtual meeting room. BusinessWeek Retrieved from http://www.businessweek.com/technology/content/apr2007/tc20070416_445840.htm

Kirkman, B. L., Rosen, B., Gibson, C.B., Tesluk, P.E, \& McPherson, S.O. (2002). Five challenges to virtual team success: Lessons from Sabre, Inc. Academy of Management Executive, 16, 67-79.

Lebie, L., Rhoades, J.A., \& McGrath, J.E. (1996). Interaction process in computermediated and face-to-face groups. Computer Supported Cooperative Work, 4(2-3), 127152.

Lind, M. (1999). The gender impact of temporary virtual work groups. IEEE Transactions of Professional Communication, 42(4), 276-285. 
Lipnack, J. \& Stamps, J. (1999). Virtual teams: The new way to work [Electronic version]. Strategy \& Leadership, 27 (1), 14-19.

Martins, L. L., Gilson, L. L., \& Maynard, M. T. (2004). Virtual teams: What do we know and where do we go from here? Journal of Management, 30, 805-835.

Mesmer-Magnus Jessica R. , Leslie A. DeChurch b, Miliani Jimenez-Rodriguez, Jessica Wildman, Marissa Shuffler (2011). A meta-analytic investigation of virtuality and information sharing in teams. Organizational Behavior and Human Decision Process $115,214-225$.

Montoya-Weiss, M.M., Massey, A.P., \& Song, M. (2001). Getting it together: Temporal coordination and conflict management in global virtual teams. Academy of Management Journal, 44, 1251-1262.

Mortensen, M. \& Hinds, P. (2001). Conflict and shared identity in geographically distributed teams. International Journal of Conflict Management, 12(3), 212-238.

Nie, N., Bent, D., \& Hull, C.H. (1970). SPSS: Statistical Package for the Social Sciences. New York, McGraw-Hill.

Pasmore, W.A. \& Purser, R.E. (1993). Designing work systems for knowledge workers. Journal for Quality and Participation, 16(4), 78-87.

Paul, S., Seetharaman, P., Samarah, I., \& Mykytyn, P.P. (2004). Impact of heterogeneity and collaborative conflict management style on the performance of synchronous global virtual teams. Information \& ManagementVolume, 41(3), 303-321.

Poole, M.S., Holmes, M., \& DeSanctis, G. (1991). Conflict management in a computersupported meeting environment. Management Science, 37, 926-953.

Powell, A., Piccoli, G., and Ives, B.(2004). Virtual teams: A review of current literature and directions for future research. The DATABASE for Advances in Information Systems, 35(1), 6-36.

Roberts, D \& Wolff, R \& Otto, O \& Steed, A (2003) Constructing a Gazebo: Supporting Teamwork in a Tightly Coupled, Distributed Task in Virtual Reality, Vol. 12, No. 6, Pages 644657, Massachusetts Institute of Technology

Quinn, J.B., Anderson, P., \& Finkelstein, S. (1996). Managing professional intellect: making the of the best. Harvard Business Review, March-April, pp. 71-80.

Saphiere, D.M.H. (1996). Productive behaviors of global business teams. International Journal of Intercultural Relations, 20, $227-259$. 
Savicki, V., Kelley, M., \& Lingenfelter, D. (1996). Gender and group composition in small task groups using computer-mediated communication. Computers in Human Behavior, 12, 209-224.

Schrage, M. (1990). Shared minds: The new technologies of collaboration. New York, Random House.

Sheppard, B. H., Hartwick, J., \& Warshaw, P.R. (1988). The theory of reasoned action: A meta-analysis of past research with recommendations for modifications and future research. Journal of Consumer

Research, 15, 325-343.

Shin, D., \& Kim, W. (2008). Applying the technology acceptance model and flow theory to Cyworld user behavior. CyberPsychology and Behavior, 11 (3), 378-382.

Siegel, J., Dubrovsky, V., Kiesler, S., \& McGuire, T. (1986). Group processes in computer-mediated communication. Organizational Behavior and Human Decision Processes, 37, 157-187.

Solomon, C. M. (2001). Managing virtual teams. Workforce, 80, 60-64.

Sproull, L. \& Kiesler, S. (1986). Reducing social context cues: Electronic mail in organizational communication. Management Science, 32(11), 1492-1512.

Taylor, S., P. A. Todd. (1995). Understanding information technology usage: A test of competing models. Inform. Systems Res. 6(2), 144-176.

Tidwell, L. C. \& Walther, J. B. (2002). Computer-mediated effects on disclosure, impressions, and interpersonal evaluations: Getting to know one another a bit at a time. Human Communication Research, 28(3), 314-348.

Townsend, A. M., DeMarie, S. M., \& Hendrickson, A. R. (1998). Virtual teams: Technology and the workplace of the future. Academy of Management Executive, 12, $17-29$.

Van Ryssen, S. \& Hayes Godar, S. (2000). Going international without going international: Multinational virtual teams. Journal of International Management, 6, 49-60.

Venkatesh, V. (2000). Determinants of perceived ease of use: integrating control, intrinsic motivation,

and emotion into the technology acceptance model. Information Systems Research, $11(4), 342-365$.

Venkatesh, V., Morris, M.G., Davis, B.G., \& F.D. Davis. (2003). User acceptance of information technology: Toward a unified view. MIS Quarterly, 27(3), 425-478. 
Walther, J. B. (1994). Anticipated ongoing interaction versus channel effects on relational communication in computer-mediated interaction. Human Communication Research, 20, 473-501.

Wellman, B. (1998). Doing It Ourselves: The SPSS Manual as Sociology's Most Influential Recent Book in Required Reading: Sociology's Most Influential Recent Books edited by Daniel Clawson. Amherst, University of Massachusetts Press, 1998, pp 71-78.

Westland, J. C. \& Clark, T. H- K.(2000). Globai Bectronic Commerce: Theory and Case Studies, MIT Press, Cambridge, MA. 